\title{
New to Poland species of the broadly defined genus Coprinus (Basidiomycota, Agaricomycotina)
}

\author{
Błażej Gierczyk*, Anna Kujawa², Andrzej Szczepkowski ${ }^{3}$ \\ 'Department of Supramolecular Chemistry, Faculty of Chemistry, Adam Mickiewizz University in Poznań, Umultowska 89b, 61-614 Poznań, \\ Poland \\ ${ }_{2}^{2}$ Institute for Agricultural and Forest Environment, Polish Academy of Sciences, Field Station in Turew, Szkolna 4, 64-000 Kościan, Poland \\ ${ }^{3}$ Department of Mycology and Forest Phytopathology, Warsaw University of Life Sciences - SGGW, Nowoursynowska 159, 02-776 Warsaw, \\ Poland
}

\section{Abstract}

The paper presents a list of 19 coprinoid fungi, found in Poland, which have not been reported earlier from this area: Coprinellus bisporiger, C. dilectus, C. heterothrix, C. radicellus, Coprinopsis annulopora, C. bellulus, C. candidolanata, C. cinereofloccosa, C. coniophora, C. goudensis, C. idae, C. iocularis, C. krieglsteineri, C. pachyderma, C. phlyctidospora, C. rugosobispora, C. scobicola, C. spilospora, Coprinus palmeranus. Illustrations and short descriptions of the species, based on the specimens examined and literature data, are given.

Keywords: Coprinus; Coprinopsis; Coprinellus; macromycetes; diversity; distribution; Poland

\section{Introduction}

The broadly circumscribed genus Coprinus Pers. includes saprobic species, characterized by deliquescent, autolysing lamellae, presence of pseudoparaphyses and darkly pigmented (dark red to almost black) spores. They grow in different habitats on various substrates: wood, soil, vegetable refuses, sawdust, litter, dung or stable manure. The molecular studies of Hopple and Vilgalys [1], Moncalvo et al. [2], Padamsee et al. [3], Larsoon and Orstadius [4], Nagy et al. [5-11] causes the splitting of the broadly defined genus Coprinus

\footnotetext{
* Corresponding author. Email: hanuman@amu.edu.pl

Handling Editor: Maria Rudawska
} 
into four genera: Coprinus Pers., Coprinellus P. Karst., Coprinopsis P. Karst., and Parasola Redhead, Vilgalys \& Hopple. From about 150 species of broadly defined Coprinus known from Europe, only 83 species have been previously mentioned from Poland [12-15]. This paper is a continuation of our studies on distribution and taxonomy of broadly defined Coprinus in Poland and presents 19 species, new to the country, which have been found within in 2010-2013.

\section{Material and methods}

The material was studied according to standard methods used in the taxonomy of fungi [16]. The microscopic structures were examined using dried material mounted in Congo Red ( $1 \%$ solution in $10 \%$ ammonia) or $10 \%$ ammonia and using fresh material mounted in water, with the aid of Bresser Science TRM 301 microscope. Descriptions and illustrations of all species were given based on the examined specimens (for multiple collections, the one used for description is specified) and data extracted from the literature (the literature data are cited in brackets). Drawings of microcharacters were made from microphotographs taken with Nikon Coolpix 950 digital camera. All measurements were made directly through the microscope under an oil immersion objective $(\times 100)$. The spore dimensions were established from measurements of 100 randomly selected, well-formed spores (the deformed or atrophied spores were excluded from analysis). The $95 \%$ population limits for the mean were calculated and the lower and upper values are given. For basidia and cystidia the extreme size values were presented. For these structures dimensions were obtained after measuring of 25-30 elements. The collected material was deposited in the private herbarium of Błażej Gierczyk. Names were given according to Vesterholt [17-19], Uljé [20] and MycoBank [21]. Information about the species distribution was given according to Vesterholt [17-19], Uljé [20], Orton and Watling [22], Doveri [23], Enderle [24], Legon and Henrici [25], Červenka [26], Nagy et al. [11], Nagy and Gorliczai [27], Keirle et al. [28], Házi et al. [29]. Unless mentioned otherwise, the literature dimensions of microscopic elements were given after Uljé [20].

\section{Results and discussion}

Coprinellus bisporiger (Buller ex P.D. Orton) Redhead, Vilgalys \& Moncalvo; Fig. 1 DESCRIPTION AND ICONOGRAPHY. [20]: 52, Fig. 34; [22]: 97-98, 144-145, Fig. 200; [30]: 76, Tab. 262, Fig. 93.34; [31]: 185-186.

MACROSCOPIC AND MICROSCOPIC FEATURES [COLL. (i)]. Basidiomata mediumsized. Pileus first ellipsoid, up to $10 \mathrm{~mm}$ high, then convex, $15-25 \mathrm{~mm}$ in diameter, pale brown to ochre brown. Stipe up to $70 \times 2.5 \mathrm{~mm}$, white. Veil absent. Spores ellipsoid to ovoid, $10-14 \times 7.0-8.5 \mu \mathrm{m}$ (lit. 10.5-13.5 ×6.5-8.5 $\mu \mathrm{m}$ ) with rounded ends and distinctly eccentric germ-pore. Basidia 2-spored, 15-30 × 7-10 $\mu \mathrm{m}$ (lit. 16-32 $\times 7-9 \mu \mathrm{m}$ ). Hymenial cystidia subglobose to ovoid. Cheilocystidia 30-55 $\times 25-35 \mu \mathrm{m}$ (lit. 25-55 $\times$ 20-35 $\mu \mathrm{m}$ ), pleurocystidia 40-55 × 30-40 $\mathrm{m}$ (lit. 40-65 $\times 28-37 \mu \mathrm{m}$ ). Pileocystidia and caulocystidia lageniform, with tapering apexes, up to $100 \times 15 \mu \mathrm{m}$. Pileocystidia apex up to $7 \mu \mathrm{m}$ wide. Clamps absent. 
SPECIMEN EXAMINED. (i) Otowo village, $0.5 \mathrm{~km}$ SE from the Lusowskie Lake, near a bicycle route, Konstantynowo forest district, Więckowice forest range, compartment No. 3, ATPOL: BD-07, one basidiocarp on stick of deciduous tree, in cultivation (litter collected on 03.10.2011), 10.10.2011, leg. \& det. B. Gierczyk (specimen: BGF/BG/111010/0001). (ii) Gdańsk city, Kowale quarter, ATPOL: DA-90, two basidiocarps on soil(?) among Phragmites in moist lawn, 01.07.2012, leg. G. Neubauer, det. B. Gierczyk (specimen: BGF/ BF/GN/120701/0001). (iii) Near Krasny Las forest ranger's lodge, Puszcza Knyszyńska forest, ATPOL: GC-11, few basidiocarps on sticks and litter on the roadside, on the bank of mid-forest water basin, in shrubs (Salix sp., Alnus sp., Picea abies, Sambucus nigra), 22.08.2010, leg. M. Gryc, det. B. Gierczyk (specimen: BGF/BF/MG/100822/0001). (iv) Ogrodniczki village, $1 \mathrm{~km}$ S, Puszcza Knyszyńska forest, ATPOL: GC-11, few basidiocarps on sticks at mixed forest margin, 10.08.2012, leg. M. Gryc, det. B. Gierczyk (specimen: BGF/BF/MG/120810/0002).

DISTRIBUTION, HABITAT AND REMARKS. This is very rare species, found in Europe (Great Britain, the Netherlands, Germany, Sweden) and North America. It occurs on branches and deciduous litter, in woods. Coprinellus bisporiger resembles C. bisporus, but differs from the later species in ecology (C. bisporus is fimicolous), somewhat narrower apex of pileocystidia (4-8 vs. 6-11 $\mu \mathrm{m}$ ) and the presence of pleurocystidia (but, according to Uljé [20], they may be absent in some collections).

Coprinellus dilectus (Fr.) Redhead, Vilgalys \& Moncalvo; Fig. 2, Fig. 3

DESCRIPTION AND ICONOGRAPHY. [22]: 84-85, 140-141, Fig. 168; [30]: 77, Tab. 263, Fig. 93.37; [31]: 188-189; [32]; [33]: III/Coprinus/19; [34]: 15-18, Fig. 1-9; [35].

MACROSCOPIC AND MICROSCOPIC FEATURES. Small species, closed pileus up to $7 \mathrm{~mm}$ high, ovoid, expanded up to $15 \mathrm{~mm}$, plane or convex, orange or orange brown, covered with granules of veil. Stipe whitish, up to $30 \times 1.5 \mathrm{~mm}$, with orange base. Spores

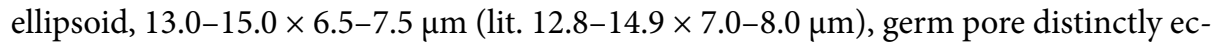
centric, spore base rounded, apex somewhat truncate. Basidia 4-spored, 25-35 × 10-12 $\mu \mathrm{m}$.

a
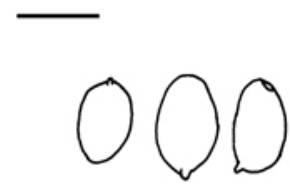

d -
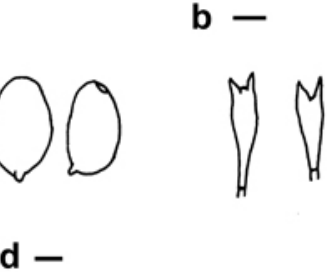

e -
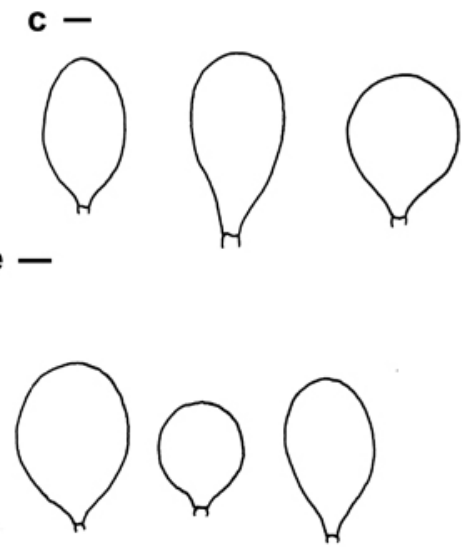

Fig. 1 Coprinellus bisporiger microcharacters: spores (a), basidia (b); pleurocystidia (c); pileocystidia (d), cheilocystidia (e). Scale bars: $10 \mu \mathrm{m}$. 
Cheilocystidia lageniform, 45-60 × 17-24 $\mu \mathrm{m}$, neck up to $10 \mu \mathrm{m}$ wide. Pleurocystidia lacking. Caulocystidia and pileocystidia lageniform, up to $90 \times 20 \mu \mathrm{m}$, pileocystidia scattered present only on cap margin. Veil composed from brown or orange, thin-walled, globose spherocystis, up to $45 \mu \mathrm{m}$. Clamps present.

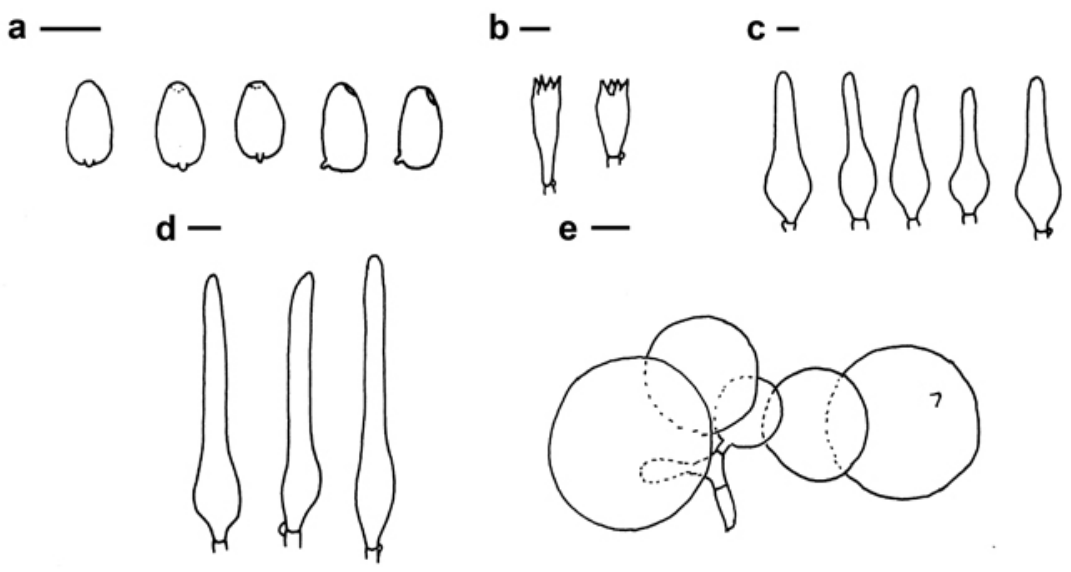

Fig. 2 Coprinellus dilectus microcharacters: spores (a), basidia (b), cheilocystidia (c), pileocystidia (d), veil (e). Scale bars: $10 \mu \mathrm{m}$.

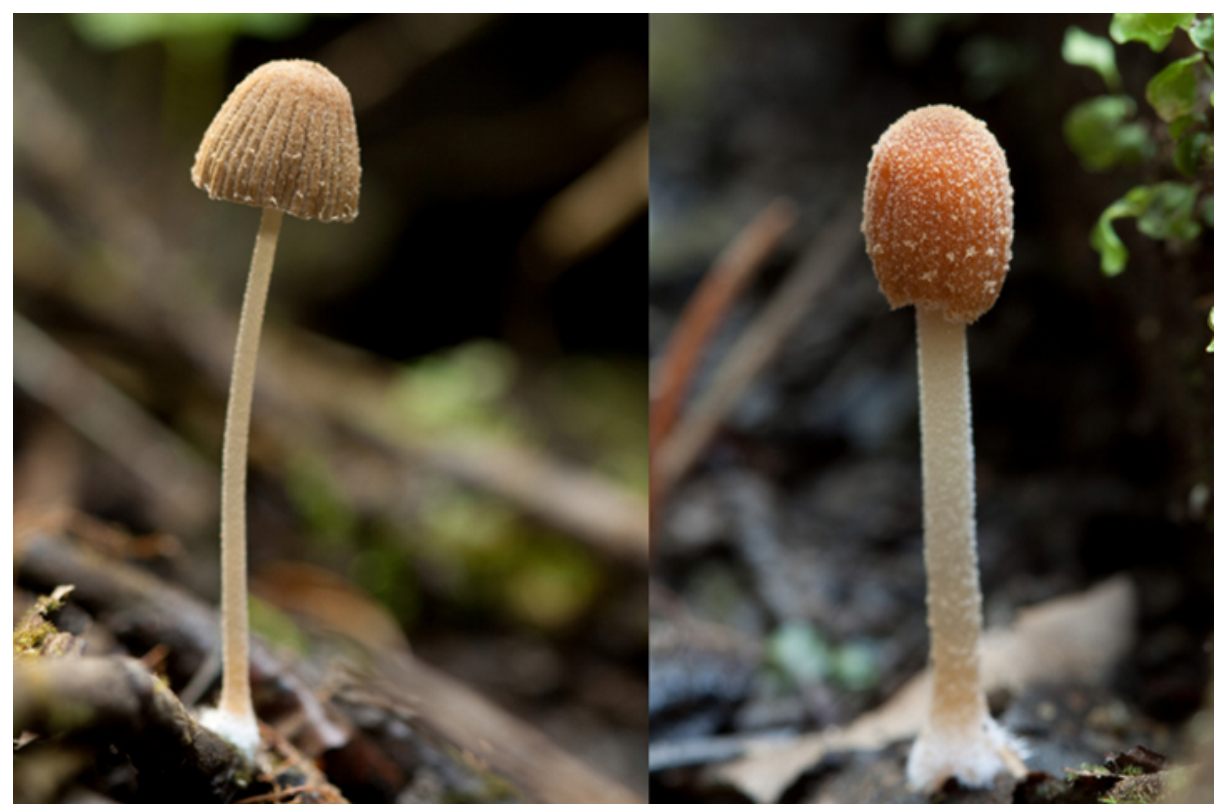

Fig. 3 Coprinellus dilectus basidiocarps from Bieszczady Mts. (05.09.2011; photo by K. Kujawa). 
SPECIMEN EXAMINED. Bieszczady Mts, Bieszczadzki National Park, slopes of Tarnica Mt. near the tourist trail, ATPOL: GG-60, a dozen of basidiocarps on wet twigs lying in helocrene spring in spruce forest, 05.09.2011, leg. A. Kujawa, det. B. Gierczyk (specimen: BGF/BdPN/110905/0002).

DISTRIBUTION, HABITAT AND REMARKS. This is very rare species, previously known only from Great Britain and Germany. It grows on very wet sticks and twigs, i.e. lying in streams or helocrene springs. It is characterized by the presence of spherocystis on the cap, presence of pileo- and caulocystidia and large, ellipsoid spores with eccentric germ pore. Some authors (Heinemann and Josserand [35]; Orton and Watling [22]) report the germ pore as central. It is the effect of truncate spore apex in some collections, which looks like a pore (see [34] for details).

Coprinellus heterothrix (Kühner) Redhead, Vilgalys \& Moncalvo; Fig. 4, Fig. 5 DESCRIPTION AND ICONOGRAPHY. [20]: 43, Fig. 17; [30]: 77, Tab. 263, Fig. 93.40A,B; [31]: 191-192; [36]: Vol. 4; 236-237, Fig. 280; [37]: 99 \& 101-102, Fig. 1-12.

MACROSCOPIC AND MICROSCOPIC FEATURES [COLL. (ii)]. Basidiomata mediumsized, expanded pileus up to $20 \mathrm{~mm}$, first conical, brown then flat to convex, greyish. Veil white, scare, as minute flocci. Stipe whitish, up to $50 \times 1.5 \mathrm{~mm}$, with slightly bulbous base. Spores ovoid, with rounded apexes, 9.0-11.0 × 5.0-6.0 $\mu \mathrm{m}$ (lit. 8.0-12.0 × 5.0-6.0 $\mu \mathrm{m})$, dark red-brown. Germ pore eccentric to central. Basidia 4-spored, 18-28 $\times 6-10 \mu \mathrm{m}$ (lit.

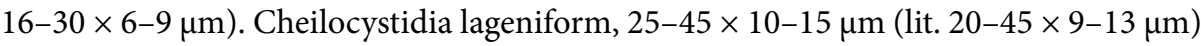
with cylindrical, thick neck, often with slightly inflated apex, pleurocystidia absent. Pileocystidia lageniform, up to $100 \times 18 \mu \mathrm{m}$ (lit. 50-110 $\times 11-20 \mu \mathrm{m}$ ), with cylindrical to clavate, about $10 \mu \mathrm{m}$ wide apex. Caulocystidia lageniform, up to $45 \times 10 \mu \mathrm{m}$. Sclerocystidia absent. Veil composed from diverticulate, cylindrical to fusiform, thin walled hyphae and clavate terminal elements. Clamps present.

SPECIMENS EXAMINED. (i) Poznań city, Wodziczki Park, near a bicycle path, ATPOL: BD-08, few basidiocarps on soil mixed with bark, under Cornus sp., 09.07.2012 \& 03.09.2012, leg. B. Kudławiec, det. B. Gierczyk (specimens: BGF/BF/BK/120709/0002 \& BGF/BF/BK/120903/0003). (ii) Gdańsk city, Chełm quarter, Kowalski Stream Valley, ATPOL: DA-90, a few basidiocarps on soil and litter near the stream, in deciduous forest (Fagus sylvatica, Carpinus betulus, Quercus sp., Sambucus nigra), 13.06.2012, leg. G. Neubauer, det. B. Gierczyk (specimen: BGF/BF/GN/120613/0001). (iii) Bieszczady Mts., Bieszczadzki National Park, Hylaty Valley, ATPOL: FG-58, one basidiocarp on the litter on the roadside near the stream bank, in mixed forest (Fagus sylvatica, Abies alba, Corylus avellana, Acer pseudoplatanus), 06.08.2011, leg. \& det. B. Gierczyk (specimen: BGF/BdPN/110806/0001). (iv) Near Krasny Las forest ranger’s lodge, Puszcza Knyszyńska forest, ATPOL: GC-11, few basidiocarps on soil in moist depression, in mixed forest with domination of deciduous trees, 07.07.2013, leg. M. Gryc, det. B. Gierczyk (specimen: BGF/BF/MG/130707/0001).

DISTRIBUTION, HABITAT AND REMARKS. This is rather common species, known from many European countries (e.g. the Netherlands, Great Britain, Denmark, Finland, Norway, Sweden) and North America, growing subfasciculate (rarely solitary) on naked soil or among grasses, in woodlands, on paths and edges of rides. It differs from the other species of section Setulosi with caps covered by diverticulate veil, the shape of pileocystidia (Coprinellus hiascens produce tapering setae on the pileus), shape of cheilocystidia 
(C. minutisporus and C. velatopruinatus have subglobose to utriform cheilocystidia) and shape of veil elements and spores (veil of C. allovelus is composed from broader, sparsely diverticulated hyphae, its spores are more elongated).

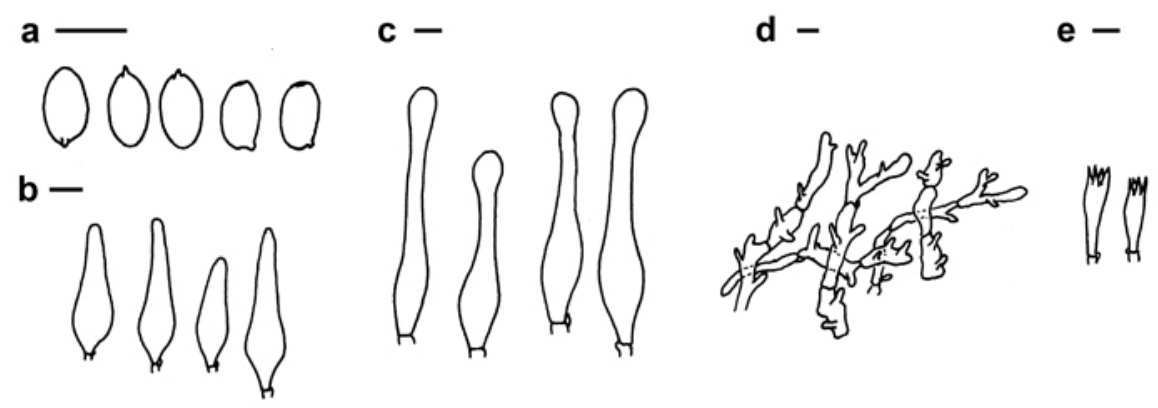

Fig. 4 Coprinellus heterothrix microcharacters: spores (a), cheilocystidia (b), pileocystidia (c), veil (d), basidia (e). Scale bars: $10 \mu \mathrm{m}$.

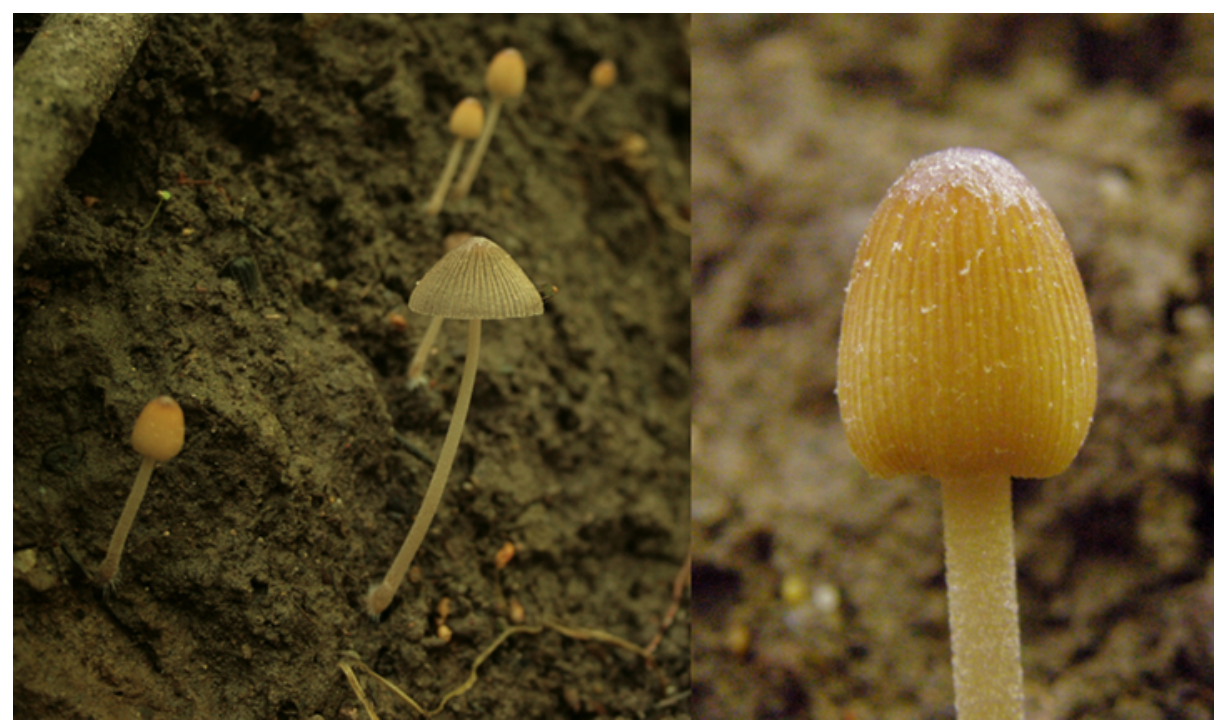

Fig. 5 Coprinellus heterothrix basidiocarps from Gdańsk city (13.06.2012; photo by G. Neubauer).

Coprinellus radicellus Házi, Nagy, Vágvölgyi \& Papp; Fig. 6, Fig. 7 DESCRIPTION AND ICONOGRAPHY. [29]: 366-369; Fig. 3.

MACROSCOPIC AND MICROSCOPIC FEATURES. Small species, cap up to 10 $\mathrm{mm}$ in diameter, first subglobose to ellipsoid, then flat, ochre brown to greyish. Stipe 
10-30 $\times 0.5 \mathrm{~mm}$, white, pubescent. Veil absent. Spores ellipsoid to subcylindrical, 7.5-10.5 × 4.5-5.3 $\mu \mathrm{m}$ (lit. 8.0-11.0 $\times 4.6-5.5 \mu \mathrm{m}$ ), germ pore central. Basidia 4-spored, clavate, $20-28 \times 8-9 \mu \mathrm{m}$ (lit. 20-28 $\times 8-9 \mu \mathrm{m}$ ). Cheilocystidia globose to clavate, scattered lageniform elements present near the lamellae margin, 10-22 $\times 9-16 \mu \mathrm{m}$ (lit. 9-20 $\times 8-14 \mu \mathrm{m})$. Pleurocystidia absent. Pileocystidia lageniform, with tapering apex, thin-walled, $40-80 \times 10-12 \mu \mathrm{m}$ (lit. 32-70 $\times 9-14 \mu \mathrm{m})$. Sclerocystidia absent. Caulocystidia similar to pileocystidia, $20-70 \times 8-12 \mu \mathrm{m}$ (lit. $25-73 \times 6-12 \mu \mathrm{m}$ ). Clamp connection absent.

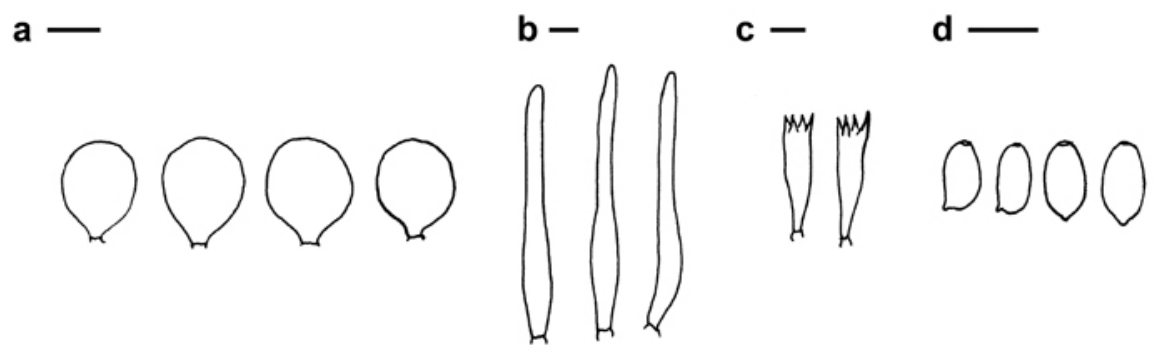

Fig. 6 Coprinellus radicellus microcharacters: cheilocystidia (a), pileocystidia (b), basidia (c), spores (d). Scale bars: $10 \mu \mathrm{m}$.

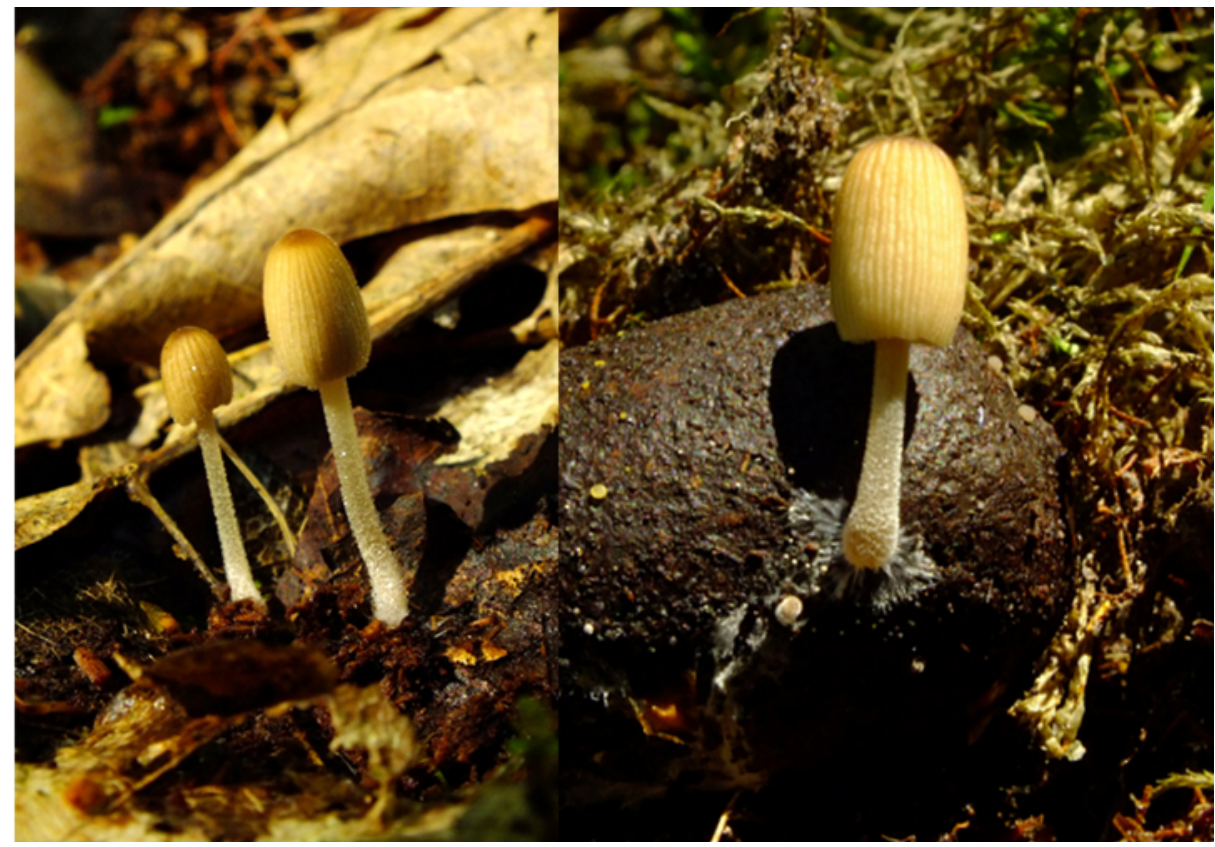

Fig. 7 Coprinellus radicellus basidiocarps from Biebrzański National Park (29.08.2012; photo by G. Domian). 
SPECIMEN EXAMINED. Biebrzański National Park, Grzędy protective unit, "Czerwone Bagno" bog, ATPOL: FB-68, few basidiocarps on moose dung, in mixed forest, 29.08.2012, leg. G. Domian, det. B. Gierczyk, (specimen: BG/BGF/GD/120910/0005).

DISTRIBUTION, HABITAT AND REMARKS. This is recently described species, originally found on old cow dung in Sweden, but also known from other localities in Sweden and Norway. It is the first finding of this species outside these two countries. It is very similar to two other Coprinellus species: C. brevisetulosus and C. pellucidus. The first has pleurocystidia and somewhat larger spores, while the second produces smaller, narrower spores and smaller, more gracile basidiocarps.

Coprinopsis annulopora (Enderle) P. Specht \& H. Schubert; Fig. 8

DESCRIPTION AND ICONOGRAPHY. [24]: 389-391; [26]; [36]: Vol. 4; 242-243, Fig. 291 (as Coprinus macrocephalus).

MACROSCOPIC AND MICROSCOPIC FEATURES [COLL. (ii)]. Basidiomata stout and firm, pileus up to $70 \mathrm{~mm}$ when expanded, first campanulate, subglobose to cylindrical, then broadly campanulate, whitish to pale grey, center ocher yellow with indistinct brownish squamules. Cap margin denticulate due to autolysis. Veil fibrillose, dirty white to grey. Stipe stout, deeply radicant, up to $150 \times 15 \mathrm{~mm}$, whitish, hollow. Spores ellipsoid to somewhat amygdaloid, 11.0-14.5 × 7.5-8.5 $\mu \mathrm{m}$ (lit. 11.6-14.0 $\times 7.2-8.2 \mu \mathrm{m}$ ), very dark, with conspicuous germ pore surrounded with annuliform collarum. Basidia 4-spored, $28-35 \times 8-12 \mu \mathrm{m}$. Cheilocystidia very poorly preserved in Polish material, subglobose, clavate to subutriform $40-100 \times 30-55 \mu \mathrm{m}$ (lit. 40-120 × 25-50 $\mu \mathrm{m}$ ). Pleurocystidia also difficult to seen, subcylindrical, clavate to lageniform 50-130 × 35-60 $\mu \mathrm{m}$ (lit. 40-150 ×30-65 $\mu \mathrm{m})$. Veil composed of cylindrical to broadly fusiform hyphae, hyaline, somewhat constricted at septa, up to $280 \times 25 \mu \mathrm{m}$. Clamps present.
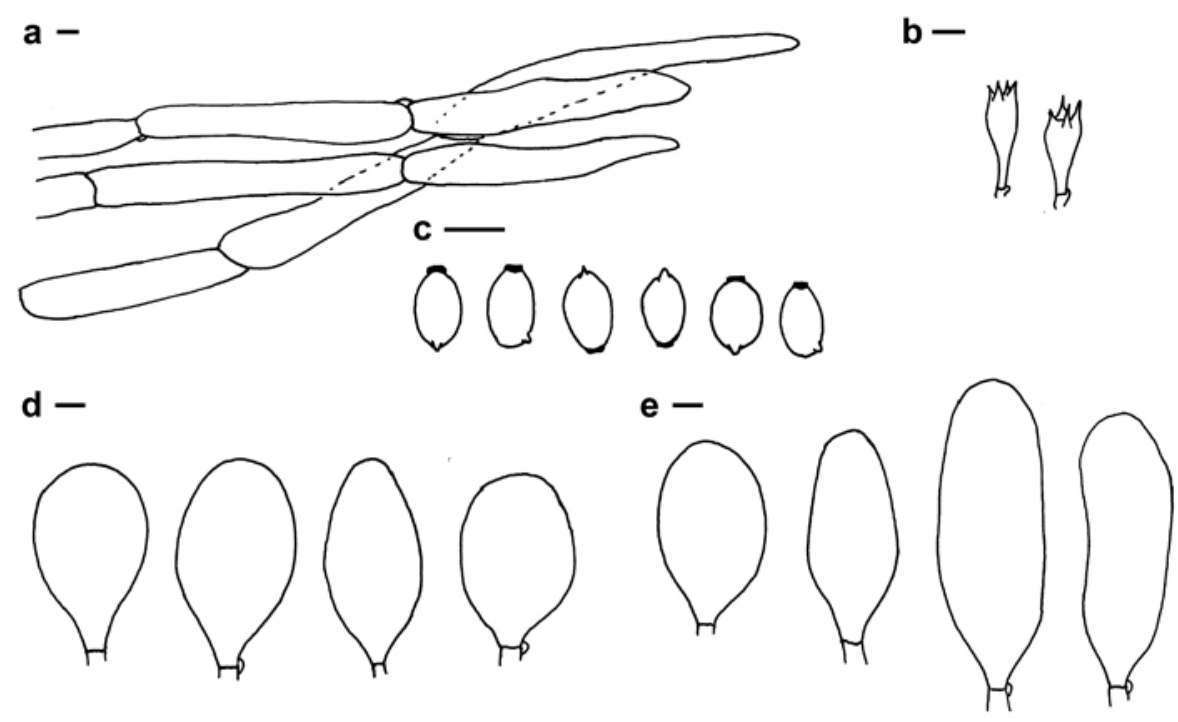

Fig. 8 Coprinopsis annulopora microcharacters: veil (a), basidia (b), spores (c), cheilocystidia (d), pleurocystidia (e). Scale bars: $10 \mu \mathrm{m}$. 
SPECIMENS EXAMINED. (i) Zakrzewo village near Poznań, E bank of the "Las Zakrzewski" forest, ATPOL: BD-07, two basidiocarps on manure at the field margin, together with C. cinereus, 15.08.2012, leg. \& det. B. Gierczyk (specimen: BGF/BG/120815/0002). (ii) Zamość village, Nowy Dwór Mazowiecki district, Kampinoski National Park, ATPOL: ED-13, few basidiocarps on horse manure, 16.10.2013, leg. T. Pachlewski, det. B. Gierczyk (specimen: BG/KPN/131016/0001).

DISTRIBUTION, HABITAT AND REMARKS. This is recently described species, until now known only from Germany, Hungary, Switzerland and Slovakia, growing on dung and manure. It is similar to two other Coprinopsis species, C. cinerea and C. macrocephala, but it is much firmer and stouter than these fungi (see Tab. 1). The photos presented by Breitenbach and Kränzlin [36] as Coprinus macrocephalus present probably the Coprinopsis annulopora specimens [24]. The typical Coprinopsis macrocephala produces smaller basidiocarps and bigger, subcylindrical spores [20]. The annuliform germ pore is observed also in some collections of $C$. cinerea, however not all authors notice it. This character is mentioned by Doveri [23], but omitted by e.g. Uljé [20] or Breitenbach and Kränzlin [36]. According to our observation, the annulus at germ pores of $C$. cinerea is less distinct and occurs only in some collections, not in all spores. These collars tend to detach from spores and to float in the mounting medium during microscope examination, especially when the samples have been prepared from dried material. It is not observed in C. annulopora, which produces persistent collars on all spores. According to Enderle [24] the mycelium shows the intersterility with that of $C$. cinerea. This author has mentioned also some differences in the germ pore annulus, observed in SEM technique, but he did not show the microphographs. Molecular studies by Nagy et al. [11] have also proved the difference between these two species. Although the material from Poland was in poor state because only the mature, partially autolysed basidiocarps were found, the macro- and microcharacters permits its unambiguous determination.

Tab. 1 Comparison of the characters of Coprinopsis annulopora, C. macrocephala and C. cinerea s.str.

\begin{tabular}{|c|c|c|c|}
\hline Character & C. annulopora & C. macrocephala & C. cinerea s.str. \\
\hline Basidiocarps & $\begin{array}{l}\text { firm and stout } \\
\text { cap up to } 70 \mathrm{~mm} \text { with } \\
\text { distinct yellow ocher center } \\
\text { stipe up to } 150 \times 15 \mathrm{~mm}\end{array}$ & $\begin{array}{l}\text { medium size } \\
\text { cap up to } 40 \mathrm{~mm} \text {, center } \\
\text { grey-brown } \\
\text { stipe up to } 150 \times 6 \mathrm{~mm}\end{array}$ & $\begin{array}{l}\text { medium size } \\
\text { cap up to } 30 \mathrm{~mm} \text {, center grey } \\
\text { brown } \\
\text { stipe up to } 100 \times 6 \mathrm{~mm}\end{array}$ \\
\hline Veil & greyish & silver & white then greyish \\
\hline Spores & $\begin{array}{l}\text { ellipsoid to subamygdaloid, } \\
\text { very dark red brown } \\
11.0-14.5 \times 7.5-8.5 \mu \mathrm{m} \\
\text { germ pore with distinct } \\
\text { annuliform collarum in all } \\
\text { spores }\end{array}$ & $\begin{array}{l}\text { ellipsoid to subcylindrical, } \\
\text { dark red brown } \\
12.2-16.8 \times 8.2-9.8 \mu \mathrm{m} \\
\text { germ pore simple }\end{array}$ & $\begin{array}{l}\text { ellipsoid to ovoid, dark red } \\
\text { brown } \\
8.4-11.8 \times 5.8-7.8 \mu \mathrm{m} \\
\text { some spores with germ pore } \\
\text { with annuliform collarum }\end{array}$ \\
\hline
\end{tabular}

Coprinopsis bellulus (Uljé) P. Roux \& Eyssart; Fig. 9, Fig. 10 DESCRIPTION AND ICONOGRAPHY. [20]: 99, Fig. 109; [30]: 88, Tab. 274, Fig. 93.81A,B; [31]: 241; [38]: 481-483, Fig. 1A-D. 
MACROSCOPIC AND MICROSCOPIC FEATURES [COLL. (ii)]. Medium-sized species. Cap up to $25 \mathrm{~mm}$ when old, first ovoid, then convex to plane, covered with white, mealy (sometimes somewhat flocculose) veil. Stipe up to $65 \times 2 \mathrm{~mm}$, white. Spores ellipsoid to ovoid, often somewhat flattened or of irregular shape, spore base rounded, apex slightly attenuated, germ pore central, 8.0-11.0 ×6.0-8.5 $\mu \mathrm{m}$ (lit. 7.5-10.5 ×6.0-8.0 $\mu \mathrm{m}$ ). Basidia 2-spored, $15-25 \times 6-10 \mu \mathrm{m}$ (lit. 15-32 $\times 7-9 \mu \mathrm{m}$ ). Hymenial cystidia absent, but in young specimens velar elements could be found on lamellar edge. Velar elements globose, smooth, up to $60 \mu \mathrm{m}$. Clamps present.

SPECIMEN EXAMINED. (i) NE part of the Puławy city, $0.1 \mathrm{~km}$ E from the railway track, ATPOL: FE-03, few basidiocarps on soil, mid-forest glade, on the slope of a hill, 10.09.2010, leg. B. Mazurek, det. B. Gierczyk (specimen: BGF/BF/BM/100910/0001). (ii) The forest complex W to the Opalenica city, between Biała Wieś and Terespotockie villages, ATPOL: BD-14, two basidiocarps on soil on grassy patch in pine forest, among Urtica dioica, 09.07.2011, leg. \& det. B. Gierczyk (specimen: BGF/BG/110709/0005). (iii) Gaj village, Gniezno district, ATPOL: CC-95, one basidiocarp on soil at the roadside of dirt road, 21.10.2012, leg. B. Kudławiec, det. B. Gierczyk (specimen: BGF/BF/BK/121021/0002).

a

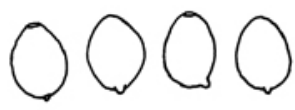

b -

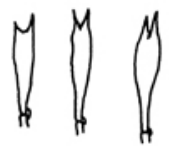

c -

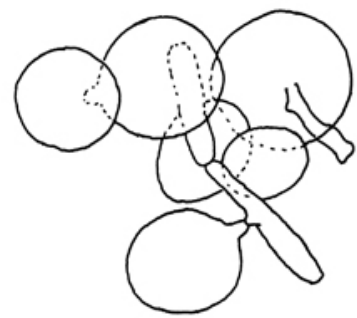

Fig. 9 Coprinopsis bellulus microcharacters: spores (a), basidia (b), veil (c). Scale bars: $10 \mu \mathrm{m}$.

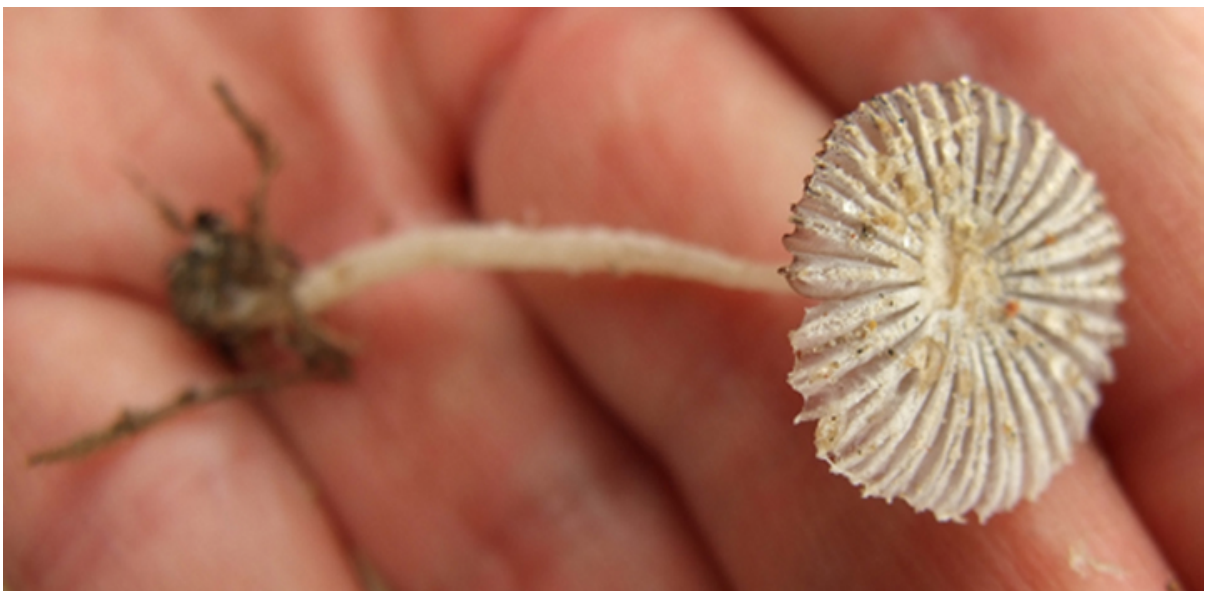

Fig. 10 Coprinopsis bellulus basidiocarps from Gaj village (21.10.2012; photo by B. Kudławiec). 
DISTRIBUTION, HABITAT AND REMARKS. This is rather rare but widespread ink-cap, found in the Netherlands, Germany, Italy, Great Britain, Hungary and Japan. It grows solitary or in bundles, on bare soil in grassy or mossy places, in woods, under shrubs or sometimes in lawns. Coprinopsis pachysperma, the second species from section Nivei with 2 -spored basidia, produces much bigger, limoniform spores.

Coprinopsis candidolanata (Doveri \& Uljé) Keirle, Hemmes \& Desjardin; Fig. 11 DESCRIPTION AND ICONOGRAPHY. [20]: 69-70, Fig. 63; [23]: 149-152.

MACROSCOPIC AND MICROSCOPIC FEATURES. Small species, expanded pileus reaching $15 \mathrm{~mm}$, first ellipsoid, then flat, whitish to grey, covered with wooly, white fibrils of veil. Stipe up to $50 \times 1 \mathrm{~mm}$, white, covered with fibrils when young. Spores ellipsoid or ovoid, rounded at apex and base, 7.5-11 ×5.0-7.0 $\mu \mathrm{m}$ (lit. 7.5-10.5 $\times 5.0-7.0 \mu \mathrm{m}$ ), with central germ pore. Basidia 4-spored, 20-35 × 8-11 $\mu \mathrm{m}$ (lit. 18-34 $\times 7-10 \mu \mathrm{m}$ ). Cheilocystidia variable, subglobose, ellipsoid, cylindrical or utriform, 25-65 $\times 20-30 \mu \mathrm{m}$ (lit. 22-70 × 17-30 $\mu \mathrm{m}$ ). Pleurocystidia ellipsoid, utriform to oblong, 35-100 × 20-35 $\mu \mathrm{m}$ (lit. 40-90 $\times 18-30 \mu \mathrm{m})$. Pileocystidia absent. Veil composed of two kinds of elements: $(i)$ thin walled, cylindrical to ovoid hyphae, $25-200 \times 15-50 \mu \mathrm{m}$, forming chains; (ii) diverticulate, subglobose to cylindrical, thin-walled elements, up to $15 \mu \mathrm{m}$ wide. Clamps absent.

SPECIMEN EXAMINED. Białowieża, Geobotanic Station of Warsaw University, ATPOL: GC-65, on sandy soil mixed with tarpan (Eurasian wild horse) dung collected in tarpans maintenance breeding (Biebrzański National Park, Grzędy protective unit, ATPOL: FB68), basidiocarps obtained in the laboratory culture, 06.09.2006, leg. A. Wiktoruk, det. B. Gierczyk (specimen: BGF/BF/AW/060906/0001).

DISTRIBUTION, HABITAT AND REMARKS. This is very rare species, previously known only from few localities (the Netherlands, Italy, Hungary and Hawaii), growing on dung of herbivores (deer, sheep). It is easy to recognize because of unique combination of characters: rather broad spores ( $Q$ of 1.45-1.55), absence of clamps and dimorphic veil elements.

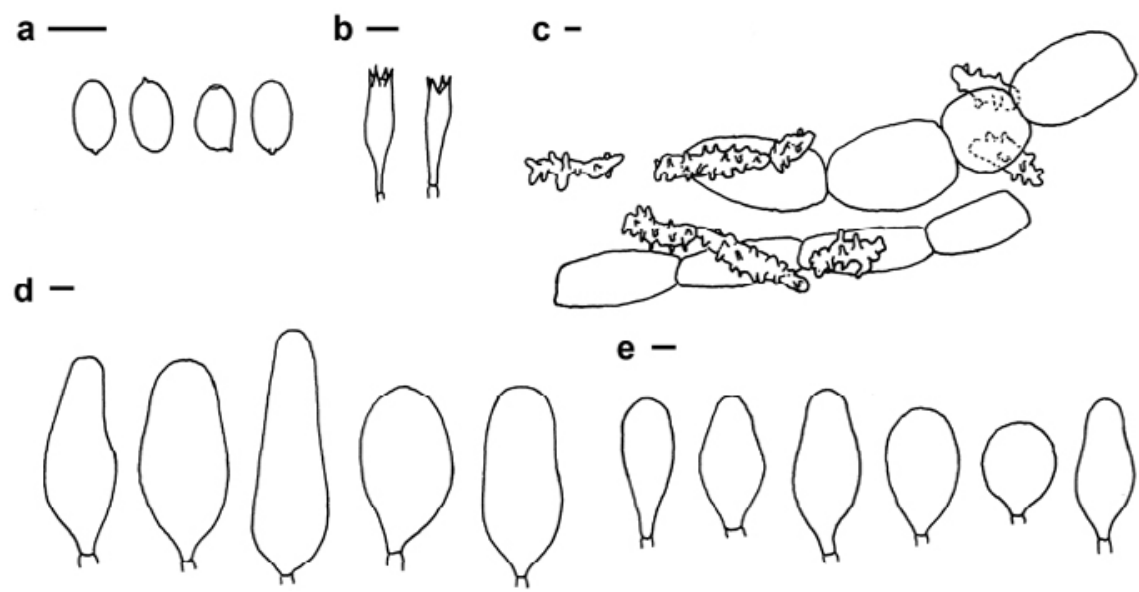

Fig. 11 Coprinopsis candidolanata microcharacters: spores (a), basidia (b), veil (c), pleurocystidia (d), cheilocystidia (e). Scale bars: $10 \mu \mathrm{m}$. 
Coprinopsis cinereofloccosa (P.D. Orton) Redhead, Vilgalys \& Moncalvo; Fig. 12, Fig. 13 DESCRIPTION AND ICONOGRAPHY. [20]: 105-106, Fig. 120; [22]: 73-74, 138-139, Fig. 153, 156 \& 160; [30]: 83, Tab. 269, Fig. 93.62A; [31]: 218-219; [36]: Vol. 4; 228-229, Fig. 268; [39]: 148, 150-151, 156, 160 \& 166, Fig. 12, 24, 33 \& 48.

MACROSCOPIC AND MICROSCOPIC FEATURES. Basidiomata medium-sized, expanded pileus up to $35 \mathrm{~mm}$ in diameter, first subglobose, then plano-convex, covered with whitish or greyish, powdery or somewhat hairy veil. Stipe white, with mealy

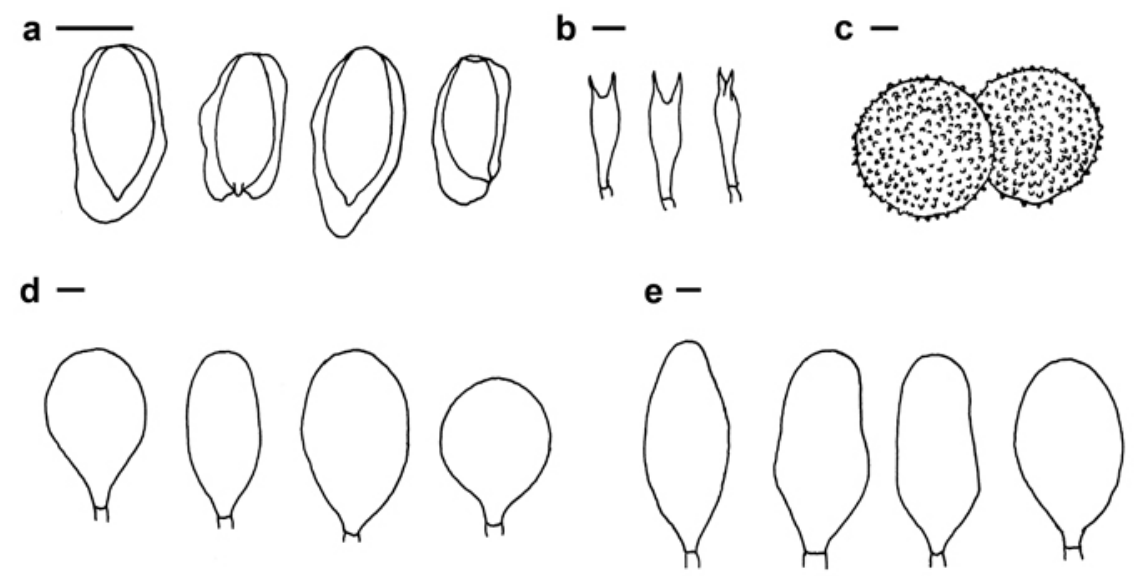

Fig. 12 Coprinopsis cinereofloccosa microcharacters: spores (a), basidia (b), veil (c), cheilocystidia (d), pleurocystidia (e). Scale bars: $10 \mu \mathrm{m}$.

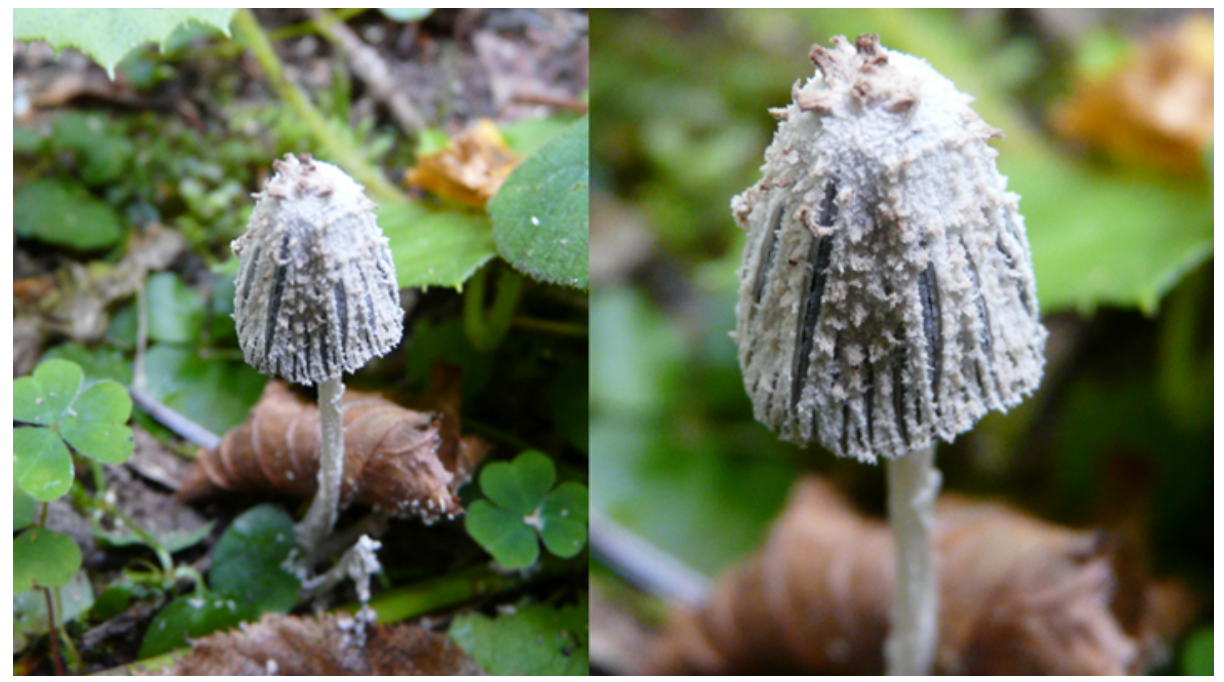

Fig. 13 Coprinopsis cinereofloccosa basidiocarps from Wola Niżna village (04.10.2011; photo by A. Hreczka). 
velar flocks, up to $50 \times 3 \mathrm{~mm}$. Spores ellipsoid to ovoid, $11.0-15.0 \times 5.5-8.0 \mu \mathrm{m}$ (lit. $11.5-14.0 \times 5.5-7.5 \mu \mathrm{m})$, with conical base and rounded apex, germ pore central, myxosporium distinct and smooth. Basidia 2-spored, 24-30 × 7-10 $\mu \mathrm{m}$ (lit. 20-32 $\times 8-9.5 \mu \mathrm{m}$ ). Cheilocystidia subglobose, ellipsoid, cylindrical to utriform, 35-100 $\times 20-42 \mu \mathrm{m}$ (lit. $30-90 \times 20-45 \mu \mathrm{m}$ ). Pleurocystidia utriform to subcylindric, 60-110 × 20-40 $\mu \mathrm{m}$ (lit. $50-120 \times 22-40 \mu \mathrm{m})$. Veil elements globose, up to $75 \mu \mathrm{m}$ wide, covered with granules persistent in $\mathrm{HCl}$. Clamp-connections absent.

SPECIMEN EXAMINED. Wola Niżna village, ATPOL: FG-33, two basidiocarps on soil and litter in submontane mixed forest (Fagus sylvatica, Abies alba) in moist place, 04.10.2011, leg. A. Hreczka, det. B. Gierczyk (specimen: BGF/BF/AH/111004/0001). DISTRIBUTION, HABITAT AND REMARKS. This is very rare species, previously found in Great Britain, Finland, Norway and Switzerland only, growing among grasses and herbs on soil. It is well characterized by two spored basidia and nipple-shaped warts on the veil elements. Coprinopsis saccharomyces, the second 2-sterigmate species belonging to section Narcotici, produces wider $(7.5-8.5 \mu \mathrm{m})$ spores with rounded base (contrary to C. cinereofloccosus spores, which has conical base).

Coprinopsis coniophora (Romagn.) Redhead, Vilgalys \& Moncalvo; Fig. 14 DESCRIPTION AND ICONOGRAPHY. [20]: 102-103, Fig. 115; [30]: 85, Tab. 271, Fig. 93.72A,B; [31]: 229-230; [33]: III/Coprinus/17.

MACROSCOPIC AND MICROSCOPIC FEATURES. Basidiomata small, pileus up to $15 \mathrm{~mm}$ in diameter, first subglobose, then convex, covered with easily detached brownish or greyish, powdery or flocky veil, pileus surface under veil whitish. Stipe white, with scattered brownish velar flocks, up to $30 \times 1 \mathrm{~mm}$. Spores amygdaliform to somewhat ovoid, 6.0-9.0 $\times 4.0-5.0 \mu \mathrm{m}$ (lit. 6.5-9.0 $\times 4.0-5.0 \mu \mathrm{m}$ ), with rounded base and apex, moderately dark, germ pore central. Basidia 4-spored, 15-25 × 5-8 $\mu \mathrm{m}$ (lit. 13-30 ×6-8 $\mu \mathrm{m})$. Cheilocystidia variable, utriform, clavate, ellipsoid, ovoid or subglobose, 10-30 × 10-15 $\mu \mathrm{m}$ (lit. 10-28 $\times 8-15 \mu \mathrm{m}$ ). Pleurocystidia absent. Veil elements globose to ellipsoid (some fusoid elements also present), up to $45 \mu \mathrm{m}$ wide, covered with granules soluble in $\mathrm{HCl}$. Clamp-connections present.

SPECIMEN EXAMINED. Poznań city, $0.6 \mathrm{~km}$ NW from Nowa Wieś Dolna quarter, ATPOL: BC-99, riparian forest with the dominance of Alnus glutinosa near the stream, dozen of basidiocarps on trunk of deciduous tree, 07.09.2011, leg. B. Kudławiec, det. B. Gierczyk (specimen: BGF/BF/BK/110907/0001).

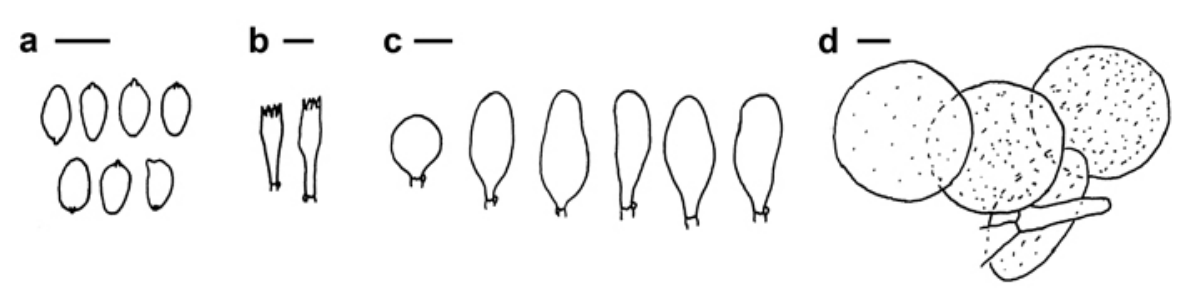

Fig. 14 Coprinopsis coniophora microcharacters: spores (a), basidia (b), cheilocystidia (c), veil (d). Scale bars: $10 \mu \mathrm{m}$. 
DISTRIBUTION, HABITAT AND REMARKS. This is rather rare but widespread species, until now known from the Netherlands, Norway, Denmark, Germany, France and Great Britain. In occurs in bundles, on wood of deciduous trees, most common on and around stumps. This species resembles Coprinellus disseminatus. From this species it differs in the absence of pileocystidia, presence of abundant, mealy veil as well as size and shape of the spores.

Coprinopsis goudensis (Uljé) Redhead, Vilgalys \& Moncalvo; Fig. 15, Fig. 16

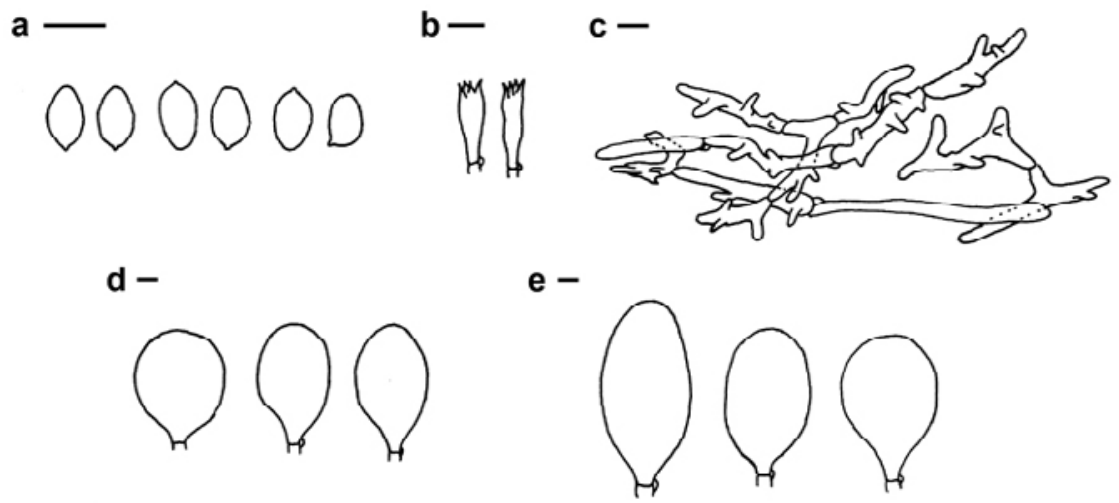

Fig. 15 Coprinopsis goudensis microcharacters: spores (a), basidia (b), veil (c), cheilocystidia (d), pleurocystidia (e). Scale bars: $10 \mu \mathrm{m}$.

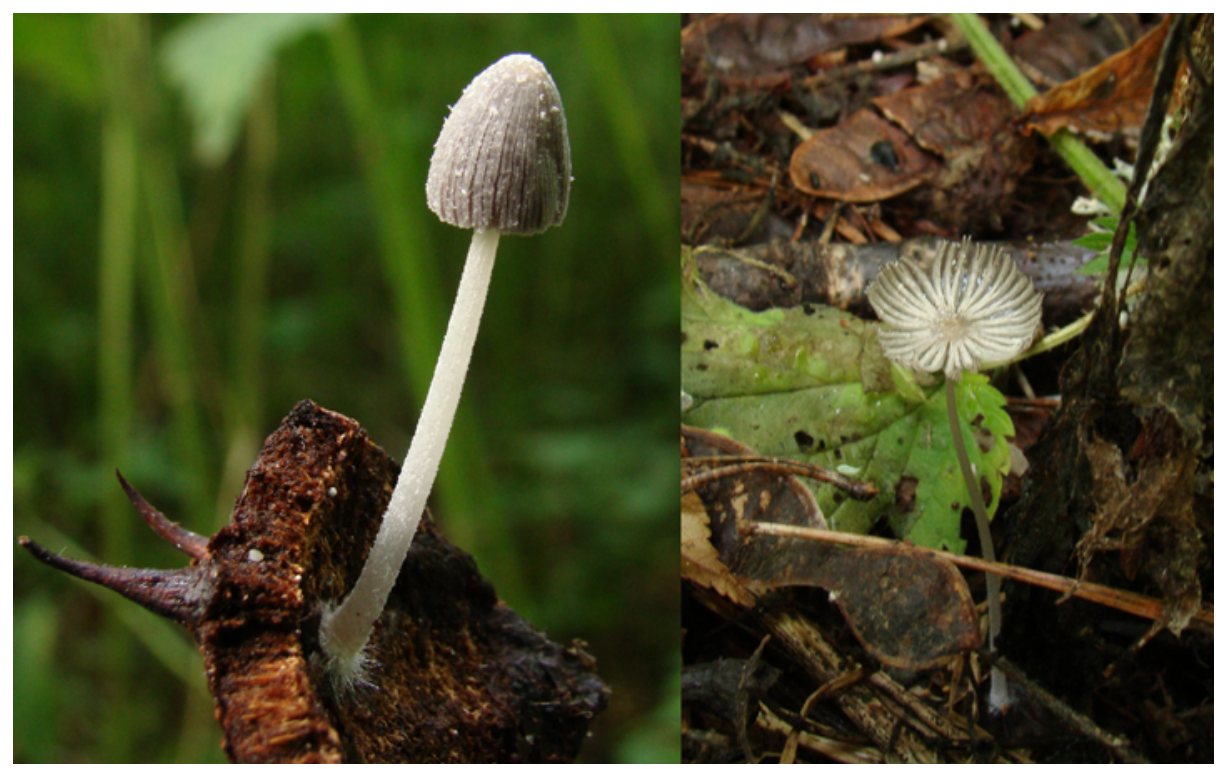

Fig. 16 Coprinopsis goudensis basidiocarps from Kotfin village (08.07.2011; photo by J. Nowicki). 
DESCRIPTION AND ICONOGRAPHY. [20]: 76-77, Fig. 72.

MACROSCOPIC AND MICROSCOPIC FEATURES. Basidiomata small, expanded pileus up to $20 \mathrm{~mm}$, first conical, then plano-convex, greyish, covered with white or whitish veil floccules. Stipe up to $30-1.5 \mathrm{~mm}$, white. Spores oblong, ellipsoid to ovoid, 7.0-10.0 $\times 4.5-7.0 \mu \mathrm{m}$ (lit. 7.0-10.5 $\times 4.5-7.0 \mu \mathrm{m}$ ), with rounded ends and central germ pore. Basidia 4-spored, $20-35 \times 6.5-8.5 \mu \mathrm{m}$ (lit. 18-40 × 7-9 $\mu \mathrm{m}$ ). Cheilocystidia subglobose, ellipsoid or ovoid, 35-70 × 25-50 $\mu \mathrm{m}$ (lit. 30-80 $\times 20-50 \mu \mathrm{m}$ ). Pleurocystidia cylindrical to oblong, 50-105 × 32-55 $\mu \mathrm{m}$ (lit. $60-100 \times 35-50 \mu \mathrm{m})$. Veil elements cylindrical, diverticulate, up to $12 \mu \mathrm{m}$ wide, thin-walled.

SPECIMEN EXAMINED. Two km SEE from Kotfin village near Radomsko city, ATPOL: DE-67, few basidiocarps on capsule epidermis and sticks of Aesculus hippocastanum in deserted, mid-forest farm, 08.07.2011, J. Nowicki, det. B. Gierczyk (specimen: BGF/BF/ JN/110708/0001).

DISTRIBUTION, HABITAT AND REMARKS. This is very rare species, previously known from the Netherlands, Denmark and Germany. It grows subfasciculate on wood of deciduous trees. Among the representatives of section Alachuani with a thin-walled veil elements it is distinguished by its habitat on wood and medium-sized, ellipsoid to ovoid spores. Coprinopsis urticicola produces somewhat narrower spores and distinctly narrower pleurocystidia.

\section{Coprinopsis idae (Uljé) Noordel.; Fig. 17}

DESCRIPTION AND ICONOGRAPHY. [20]: 97-98, Fig. 106.

MACROSCOPIC AND MICROSCOPIC FEATURES. Basidiomata small and fragile, cap up to $8 \mathrm{~mm}$ when expanded, first conical or campanulate, becoming applanate with age, first white, covered with powdered veil, then greyish. Stipe up to $40 \times 1 \mathrm{~mm}$, whitish. Spores broadly ellipsoid to oval, 7.0-9.5 × 5.0-7.0 $\mu \mathrm{m}$ (lit. 6.5-9.5 × 4.5-7.0 $\mu \mathrm{m}$ ), rounded at ends, pale red-brown, germ pore central. Basidia 4-spored, 20-25 $\times 7-9 \mu \mathrm{m}$ (lit. 16-28 $\times 6.5-8 \mu \mathrm{m}$ ). Cheilo- and pleurocystidia of the same shape and size, subglobose, to utriform, 30-50 × 15-30 $\mu \mathrm{m}$ (lit.: cheilocystidia $25-50 \times 16-28 \mu \mathrm{m}$; pleurocystidia 25-55 $\times 14-28 \mu \mathrm{m})$. Veil composed of colourless, smooth, spherical to broadly ellipsoid elements, up to $50 \times 40 \mu \mathrm{m}$, intermixed with scattered, branched thin-walled hyphae. Clamps absent.

\section{a}

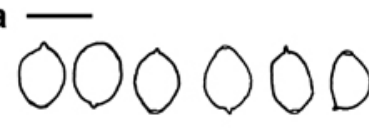

d -

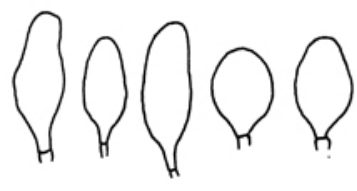

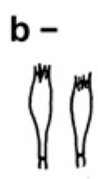

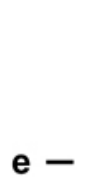

c -
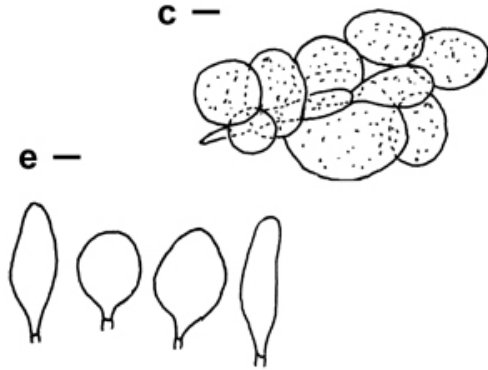

Fig. 17 Coprinopsis idae microcharacters: spores (a), basidia (b), veil (c), cheilocystidia (d), pleurocystidia (e). Scale bars: $10 \mu \mathrm{m}$. 
SPECIMEN EXAMINED. Two km NEE from Stara Jabłonka village, near the road to Zawada (Miedzichowo district), ATPOL: BC-91, one basidiocarp on litter in Robinia pseudoacacia forest, 24.07.2011, leg. \& det. B. Gierczyk (specimen: BGF/BG/110724/0002). DISTRIBUTION, HABITAT AND REMARKS. This is very rare species, previously known from the Netherlands, Belgium, Russia and Spain. It grows mostly terrestrial, but also on litter, in lawns and forests. Polish collection consists of only one, old basidiocarp, however the macro- and microscopical characters indicate a correct determination.

Coprinopsis iocularis (Uljé) Noordel.; Fig. 18, Fig. 19
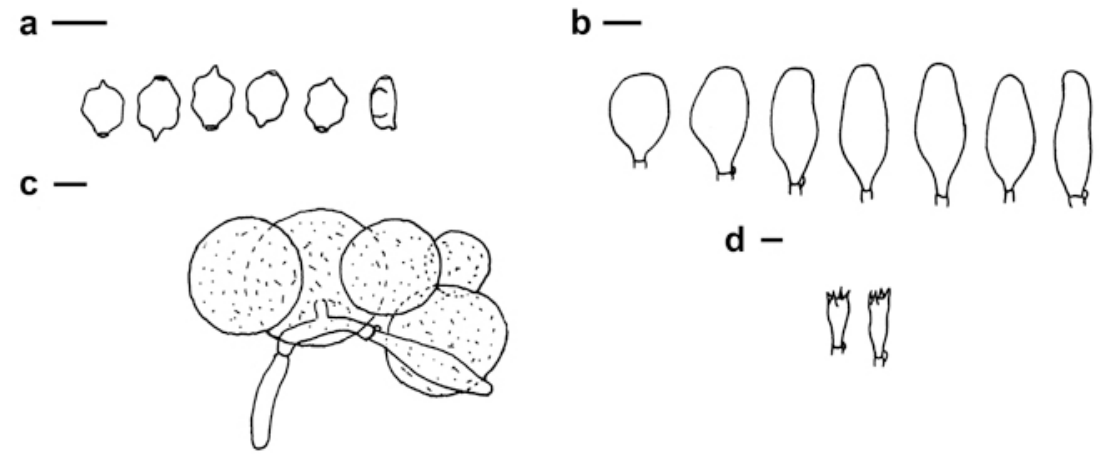

d -

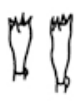

Fig. 18 Coprinopsis iocularis microcharacters: spores (a), cheilocystidia (b), veil (c), basidia (d). Scale bars: $10 \mu \mathrm{m}$.

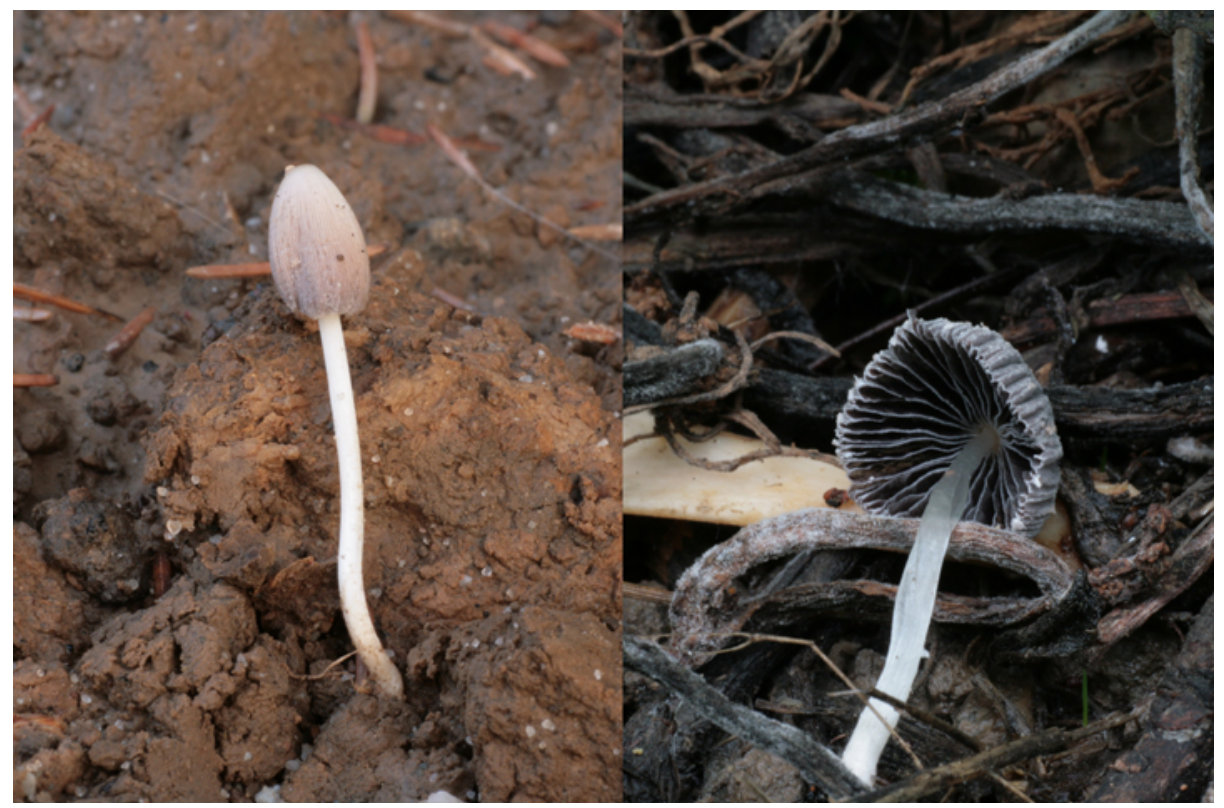

Fig. 19 Coprinopsis iocularis basidiocarps from Skawina village (12.07.2011; photo by W. Czerniawski). 
DESCRIPTION AND ICONOGRAPHY. [20]: 102, Fig. 114; [38]: 485-486, Fig. 3. MACROSCOPIC AND MICROSCOPIC FEATURES. Basidiomata medium-sized, pileus up to $30 \mathrm{~mm}$ when expanded, first conical, then convex to plane, covered with white, powdery veil, becoming grey with age. Stipe white, up to $50 \times 1.5 \mathrm{~mm}$. Spores 6.0-9.0 × 5.0-6.0 $\mu \mathrm{m}$ (lit. 6.0-8.5 ×5.0-6.0 $\mu \mathrm{m}$ ), somewhat hexagonal in frontal view, flattened, with distinct, rounded, lateral nodules (two on each side), with conical base and truncate apex, germ pore central. Basidia 4-spored, $12-29 \times 5-8 \mu \mathrm{m}$ (lit. 13-32 $\times 6-8 \mu \mathrm{m}$ ). Cheilocystidia mostly utriform but also clavate, ellipsoid or subglobose, $22-40 \times 8-17 \mu \mathrm{m}$ (lit. 20-35 × 8.5-15.5 $\mu \mathrm{m}$ ). Pleurocystidia absent. Veil elements globose, up to $45 \mu \mathrm{m}$ wide, smooth or covered with scattered granules soluble in HCl. Clamp-connections present. SPECIMEN EXAMINED. Skawina village near Kraków city, Tyniecka street, DF-78, one basidiocarp on soil, on lawn, under Taxus baccata shrub, 12.07.2011, leg. W. Czerniawski, det. B. Gierczyk (specimen: BGF/BF/WCz/110712/0002).

DISTRIBUTION, HABITAT AND REMARKS. This is very rare species, previously known only from the Netherlands, where it was found on several localities. It grows solitary or in small groups on soil, on lawns. Unique spores shape makes it very easy to recognize.

Coprinopsis krieglsteineri (Bender) Redhead, Vilgalys \& Moncalvo; Fig. 20, Fig. 21 DESCRIPTION AND ICONOGRAPHY. [20]: 61, Fig. 50; [30]: 79, Tab. 265, Fig. 93.47; [31]: 199-200; [40]: 193-195, Fig. 14.

MACROSCOPIC AND MICROSCOPIC FEATURES [COLL. $(i)$ ]. Basidiomata small and fragile. Pileus up to $10 \mathrm{~mm}$ high at first, ellipsoid then flat to concave, up to $15 \mathrm{~mm}$, whitish to greyish with darker, brown center, covering with arachnoid veil. Stipe white, tapering, up to $50 \times 1 \mathrm{~mm}$, with small flocci. Spores ellipsoid to ovoid, 10.0-13.5 $\times 6.0-7.0 \mu \mathrm{m}$ (lit. 9.5-14.0 $\times 6.0-7.0 \mu \mathrm{m})$, with rounded ends. Germ pore central. Basidia 4-spored, 25-30 × 8-10 $\mu \mathrm{m}$ (lit. 22-43 × 9-11 $\mu \mathrm{m}$ ). Cheilocystidia variable, ellipsoid to cylindrical, subglobose, utriform or conical, 30-95 × 20-50 $\mu \mathrm{m}$ (lit. 35-115 × 18-55 $\mu \mathrm{m}$ ). Pleurocystidia utriform to cylindrical, $90-150 \times 30-50 \mu \mathrm{m}$ (lit. 70-160 $\times 28-55 \mu \mathrm{m})$. Veil composed of cylindrical to somewhat fusiform, chain-forming elements, up to $180 \times 20$ $\mu \mathrm{m}$. Stipe covering made from diverticulated elements. Clamps present.

SPECIMENS EXAMINED: (i) $2 \mathrm{~km}$ SSE from Będlewo village near Stęszew, at the dirt road to Będlewo forest ranger's lodge, ATPOL: BD-27, a dozen of basidiocarps on sticks and litter in deciduous forest (Populus sp., Fraxinus excelsior, Corylus avellana), 02.10.2011, leg. \& det. B. Gierczyk (specimen: BGF/BG/111002/0001). (ii) Forest Experimental Station of the Warsaw University of Life Sciences - SGGW in Rogów (LZD), Rogów forest district, Strzelna forest range, compartment No. 152, ATPOL: DD-69, a dozen of basidiocarps on soil on the roadside of dirt road in larch forest, 26.09.2011, leg. A. Szczepkowski, det. B. Gierczyk (specimen: BGF/BF/ASz/110926/0001).

DISTRIBUTION, HABITAT AND REMARKS. This is very rare ink-cap, previously known only from the Netherlands, Germany, Denmark, Great Britain and Hungary. It occurs solitary or subfasciculate on litter, humus and wood-chips in deciduous forest. It may be confused with small specimens of Coprinopsis lagopus from which it differs in narrower spores and tiny, arachnoid veil. We have studied some ink-cap collections from northern Poland having intermediate characters - the specimens are smaller than C. lagopus basidiomata but they are not so fragile as these produced by C. krieglsteineri, the veil is conspicuous and well developed (as in C. lagopus) but the spore dimensions 
a

b - $\quad$ c -
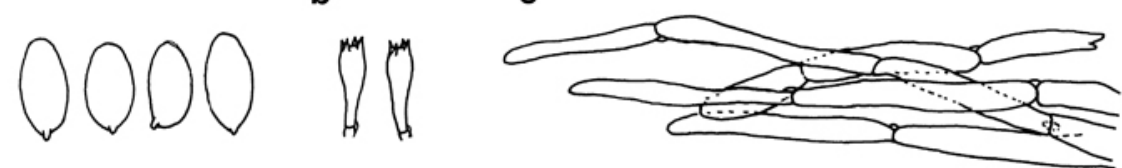

d -
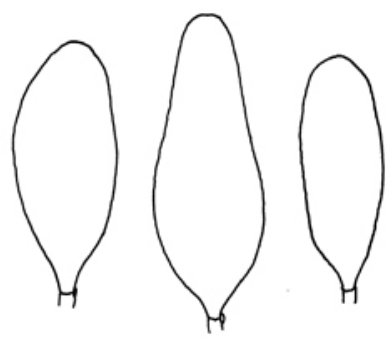

e -

f -

Fig. 20 Coprinopsis krieglsteineri microcharacters: spores (a), basidia (b), veil (c), pleurocystidia (d), cheilocystidia (e), stipe covering (f). Scale bars: $10 \mu \mathrm{m}$.

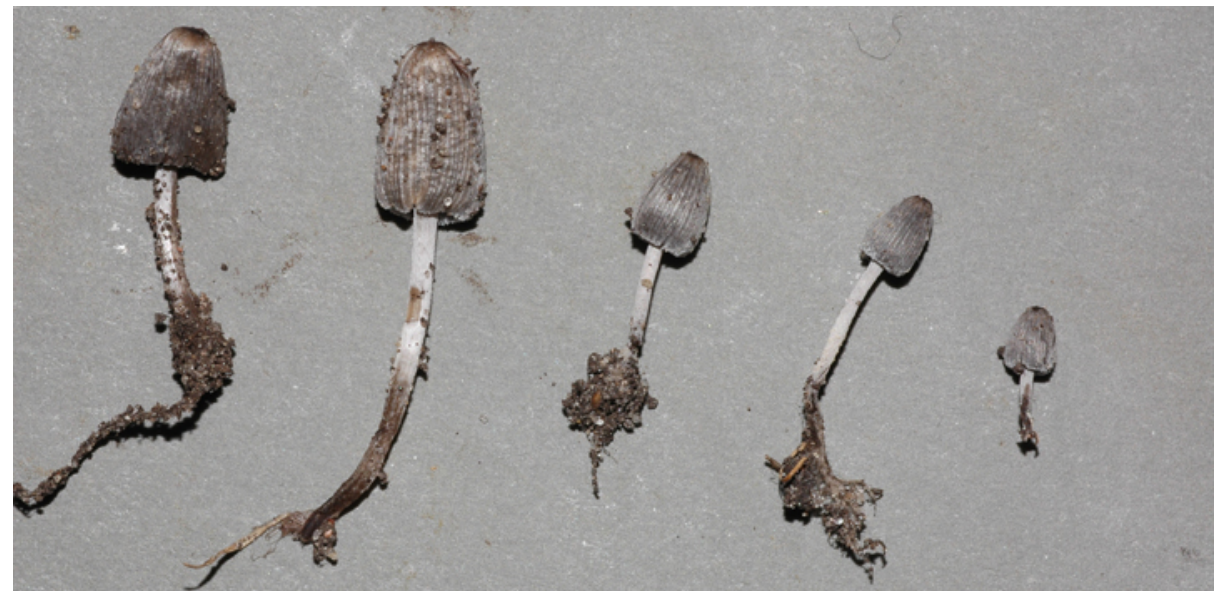

Fig. 21 Coprinopsis krieglsteineri basidiocarps from surroundings of Będlewo village (02.10.2011; photo by B. Gierczyk).

are close to that of C. krieglsteineri (av. 10-12 ×6-6.5 $\mu \mathrm{m}$ ). These specimens need further, detailed studies.

Coprinopsis pachyderma (Bogart) Redhead, Vilgalys \& Moncalvo; Fig. 22, Fig. 23 DESCRIPTION AND ICONOGRAPHY: [32]; [40]: 195-198, Fig. 16; [41]: 274-277, Fig. 9; [42]: 25, Fig. 1. 
MACROSCOPIC AND MICROSCOPIC FEATURES [COLL. (i)]. Medium-sized species, pileus up to $30 \mathrm{~mm}$ when expanded, first ellipsoid or cylindrical, then convex, plane or revolute, greyish, covered with hairy whitish veil, brownish at center. Stipe white, up to $70 \times 2.5 \mathrm{~mm}$. Spores ovoid or ellipsoid, $9.0-13.0 \times 6.0-8.5 \mu \mathrm{m}$ (lit. 8.8-13.1 $\times 5.7-8.3 \mu \mathrm{m}$ ), with rounded to slightly tapering base and rounded to truncate apex. Germ pore central to slightly eccentric. Basidia 4-spored, 20-32 × 6-10 $\mu \mathrm{m}$ (lit. 24-34× 6-9 $\mu \mathrm{m})$. Cheilocystidia variable, subglobose, utriform, ellipsoid, oblong or cylindrical,

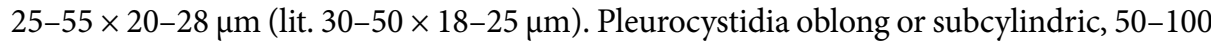
$\times 25-38 \mu \mathrm{m}$ (lit. 60-90 $\times 24-35 \mu \mathrm{m}$ ). Veil composed of thin-walled, cylindrical, elongate elements, $20-200 \times 6-35 \mu \mathrm{m}$ (lit. 20-180 ×6-40 $\mu \mathrm{m}$ ) forming chains with constricted septa. Terminal elements fusiform, ovoid or cylindrical, with $1 \mu \mathrm{m}$ thick, yellowish walls. Clamps present.

SPECIMENS EXAMINED. (i) Poznań city, Sołacki Park, ATPOL: BD-08, a dozen of basidiocarps on soil and litter under Cornus sp., 21.06.2011, 22.06.2011, 09.08.2011, 25.04.2012, 03.09.2012, 17.09.2012 \& 30.04.2013, leg. B. Kudławiec \& B. Gierczyk, det. B. Gierczyk (specimens: BGF/BF/BK/110621/0001, BGF/BF/BK/110622/0001, BGF/ $\mathrm{BF} / \mathrm{BK} / 110809 / 0001, \mathrm{BGF} / \mathrm{BF} / \mathrm{BK} / 120425 / 0001, \mathrm{BGF} / \mathrm{BF} / \mathrm{BK} / 120903 / 0005, \mathrm{BGF} / \mathrm{BF} /$ BK/120917/0001, BGF/BG/130430/0001). (ii) Poznań city, Wodziczki Park, near a bicycle path, ATPOL: BD-08, a dozen of basidiocarps on soil and litter under Cornus sp., 09.07.2012, 03.09.2012 \& 07.09.2012, leg. B. Kudławiec, det. B. Gierczyk (specimens: BGF/BF/BK/120709/0001, BGF/BF/BK/120903/0001, BGF/BF/BK/120907/0001).

DISTRIBUTION, HABITAT AND REMARKS. This species was found only twice in Europe - in Great Britain. In USA it is known only from type locality. It occurs on woody debris. It is characterized by thickened walls of veil hyphae and short, vesiculous pleurocystidia. It may be confused with Coprinopsis lagopus from which it differs by the thick walls of veil end elements, somewhat shorter spores (the $Q_{\mathrm{av}}$ is 1.40-1.60 for C. pachysperma and 1.55-1.80 for C. lagopus) with slightly conical base and distinctly smaller cystidia.

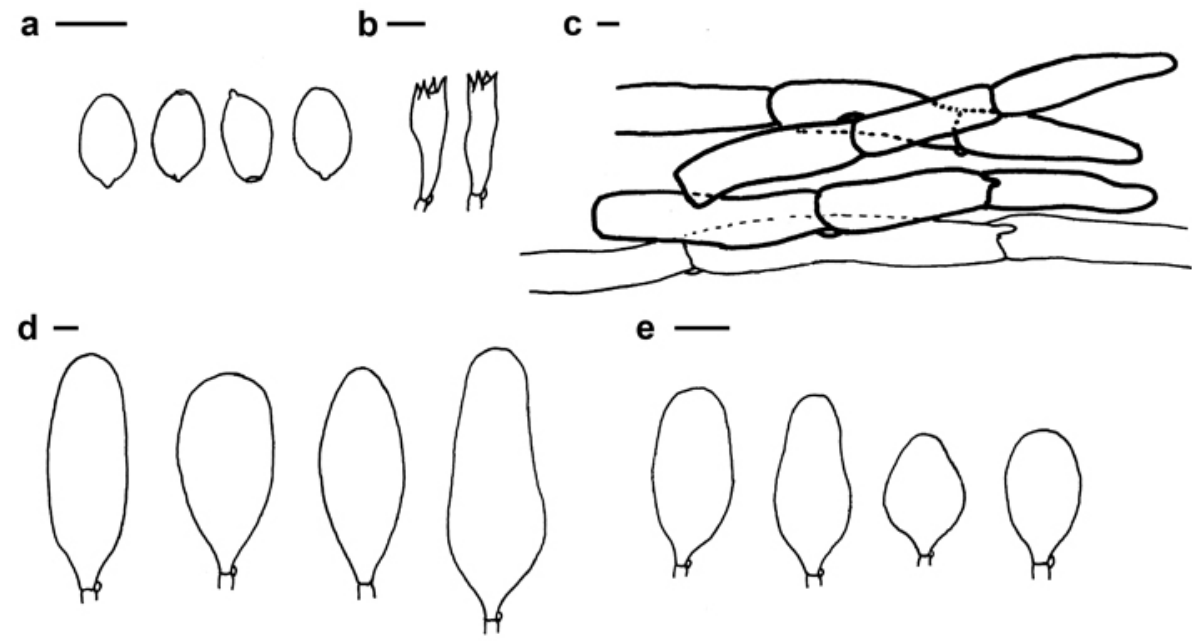

Fig. 22 Coprinopsis pachyderma microcharacters: spores (a), basidia (b), veil (c), pleurocystidia (d), cheilocystidia (e). Scale bars: $10 \mu \mathrm{m}$. 

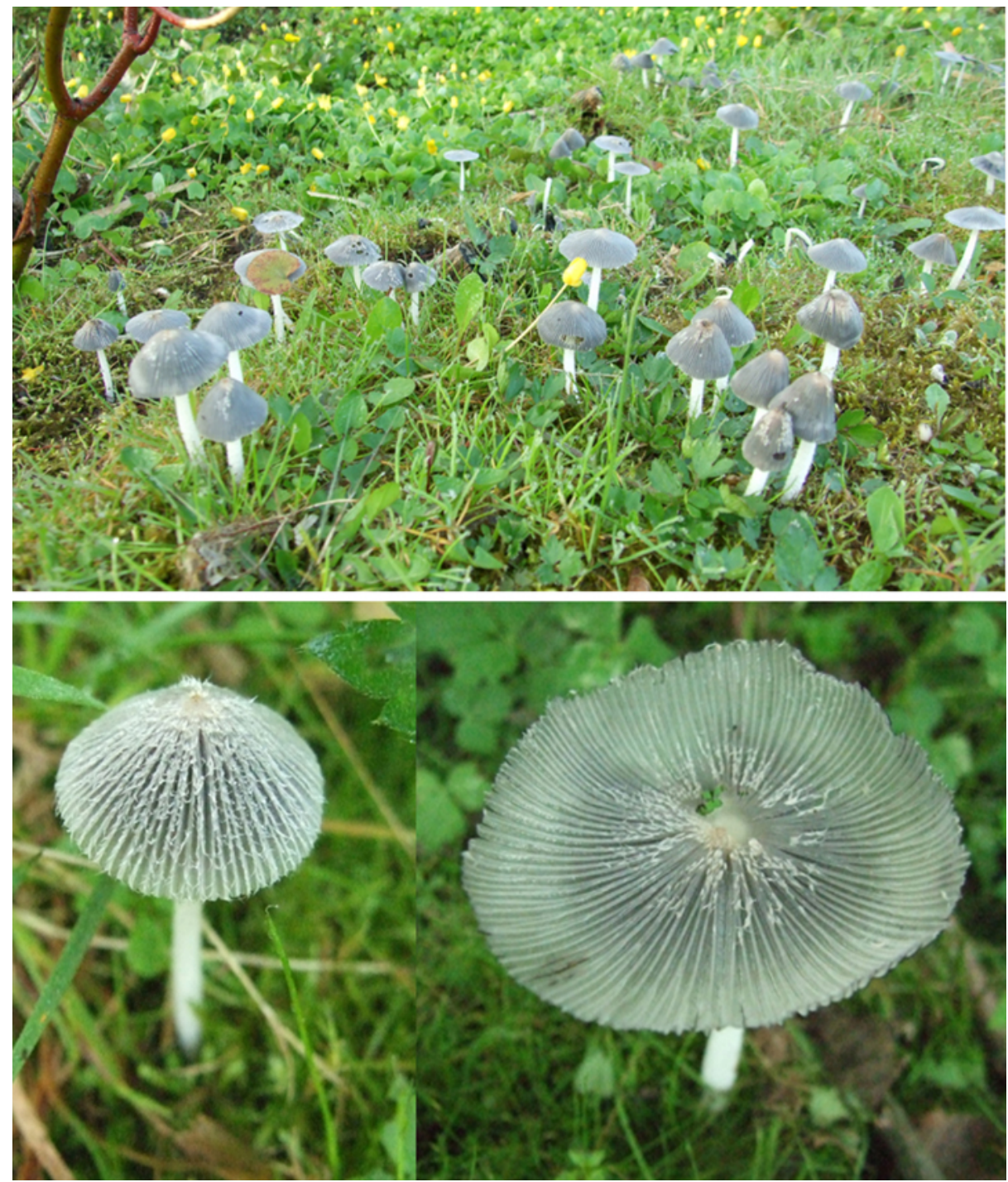

Fig. 23 Coprinopsis pachyderma basidiocarps from Poznań city (25.04.2012; photo by B. Kudławiec).

Coprinopsis phlyctidospora (Romagn.) Redhead, Vilgalys \& Moncalvo; Fig. 24, Fig. 25 DESCRIPTION AND ICONOGRAPHY. [20]: 83-84, Fig. 83; [22]: 36, 124-125, Fig. 51; [30]: 71, Tab. 257, Fig. 93.9; [31]: 157-158.

MACROSCOPIC AND MICROSCOPIC FEATURES [COLL. (i)]. Medium-sized ink-cap, forming pileus up to $30 \mathrm{~mm}$ in diameter, first ovoid, expanding to applanate or convex, white to grey with darker center, covered with whitish to greyish veil, forming discrete flocci. Stipe up to $90 \times 2.5 \mathrm{~mm}$, white. Spores amygdaliform, truncate, with central germ pore and distinct warty ornamentation, 8.0-12.0 × 6.0-8.5 $\mu \mathrm{m}$ (lit. 7.5-11.0 × 5.5-8.0 $\mu \mathrm{m}$ ). 
a

b -

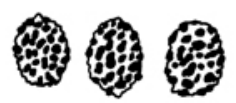

d -

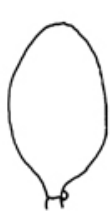

$$
\text { (x) }
$$

c-

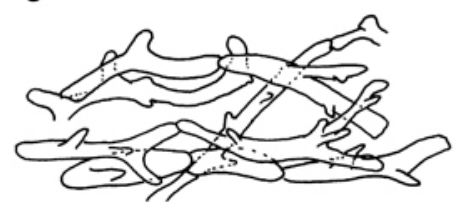

e -

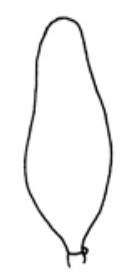

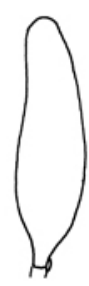

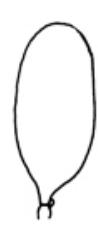

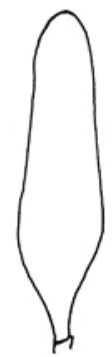

Fig. 24 Coprinopsis phlyctidospora microcharacters: spores (a), basidia (b), veil (c), cheilocystidia (d), pleurocystidia (e). Scale bars: $10 \mu \mathrm{m}$.

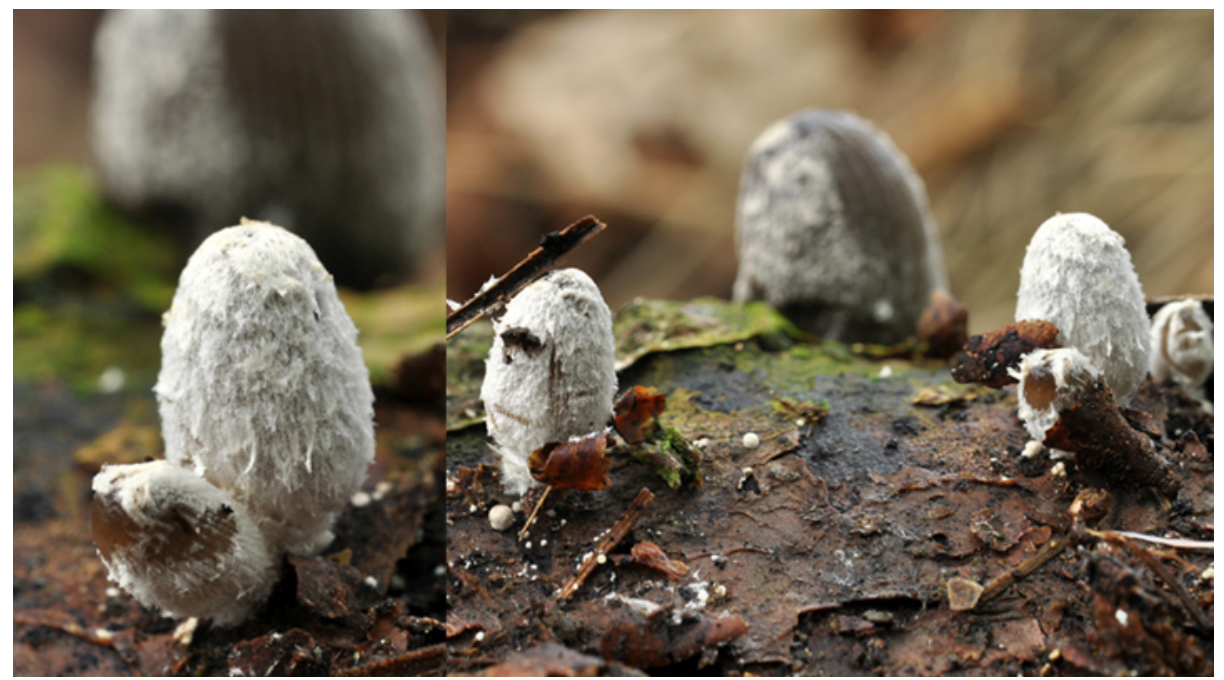

Fig. 25 Coprinopsis phlyctidospora young basidiocarps from "Kąty Rybackie" natural reserve (17.08.2012; photo by M. Wantoch-Rekowski).

Basidia 4-spored, 20-30 × 8-10 $\mu \mathrm{m}$ (lit. 20-35 × 7-9 $\mu \mathrm{m}$ ). Cheilocystidia subglobose to utriform, 30-80 $\times 20-30 \mu \mathrm{m}$ (lit. 30-70 $\times 15-30 \mu \mathrm{m}$ ). Pleurocystidia ellipsoid, utriform to cylindrical, $50-100 \times 20-40 \mu \mathrm{m}$ (lit. 50-110 × 20-35 $\mu \mathrm{m}$ ). Veil thin-walled, composed of diverticulated hyphae, up to $10 \mu \mathrm{m}$ wide. Clamps present. 
SPECIMENS EXAMINED. (i) Otowo village, $0.5 \mathrm{~km}$ SE from the Lusowskie Lake, near a bicycle route, Konstantynowo forest district, Więckowice forest range, compartment No. 3, ATPOL: BD-07, few basidiocarps on the sticks of deciduous tree in mixed forest (Populus sp., Tilia sp., Corylus avellana, Pinus sylvestris), near a dirt road, among Urtica dioica, 24.09.2011 \& 08.10.2011, leg. \& det. B. Gierczyk (specimens: BGF/BG/110924/0010 \& BGF/BG/111008/0001). (ii) "Kąty Rybackie" nature reserve, Nowy Dwór Gdański country, ATPOL: DA-84, few basidiocarps on buried sticks in dead pine forest (cormorants' colony), 17.08.2012, leg. M. Wantoch-Rekowski, det. B. Gierczyk (specimen: BGF/ BF/MWR/120817/0003).

DISTRIBUTION, HABITAT AND REMARKS. This is widespread and not rare species in Europe, known also from Japan, growing on woody debris (mainly dead branches) and on burnt places. Coprinopsis echinospora, the second species of the section Alachuani with 4-spored basidia and ornamented spores, produces amygdaliform spores.

Coprinopsis rugosobispora (Geesink \& Imler) Redhead, Vilgalys \& Moncalvo; Fig. 26, Fig. 27

DESCRIPTION AND ICONOGRAPHY: [20]. 84, Fig. 84.

MACROSCOPIC AND MICROSCOPIC FEATURES [COLL. (i)]. Medium-sized species. Pileus up to $25 \mathrm{~mm}$ when expanded, first ovoid, then plane, white, becoming greyish with age. Veil whitish, forming small flocci. Stipe up to $70 \times 2.5 \mathrm{~mm}$, white. Spores coarsely warty, ovoid, with rounded ends and central germ pore, $9.0-12.0 \times$

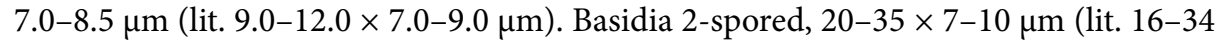
$\times 6-8 \mu \mathrm{m}$ ). Cheilocystidia subglobose, utriform to cylindrical 35-60 × 25-35 $\mu \mathrm{m}$ (lit. 30-70 $\times 20-35 \mu \mathrm{m})$. Pleurocystidia ovoid, utriform to cylindrical, 50-100 $\times 30-45 \mu \mathrm{m}$ (lit. 50-80 $\times 30-40 \mu \mathrm{m}$ ). Veil composed of thin-walled, diverticulated hyphae, up to 10 $\mu \mathrm{m}$ wide. Clamps present.

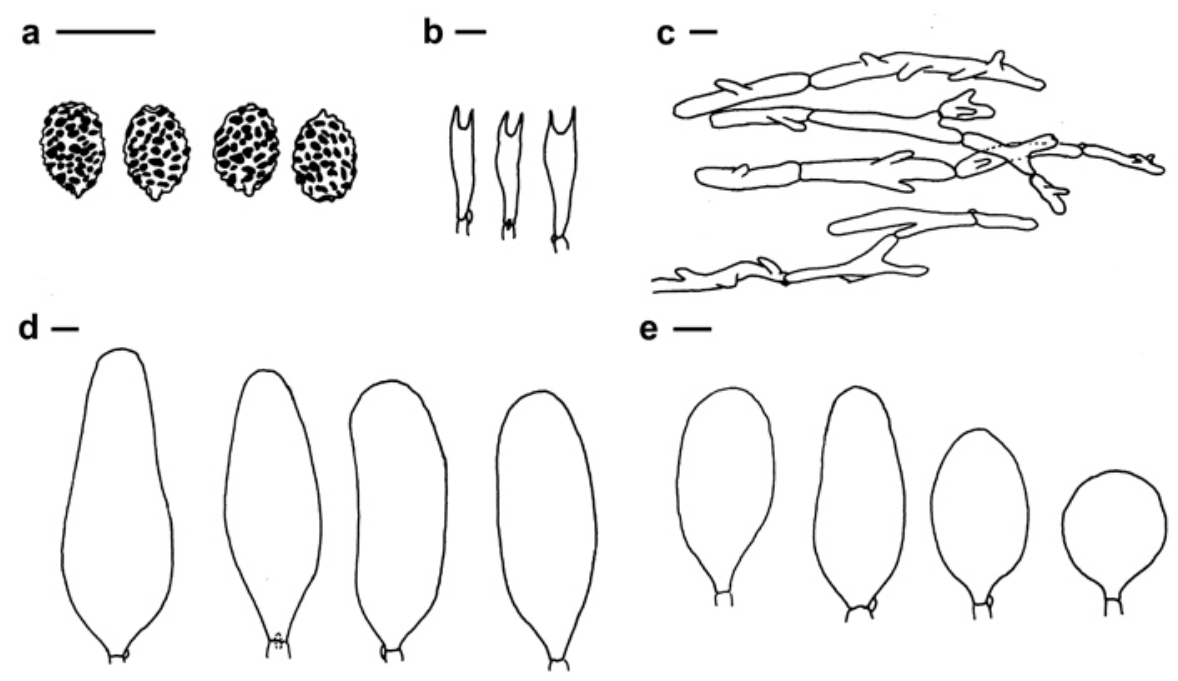

Fig. 26 Coprinopsis rugosobispora microcharacters: spores (a), basidia (b), veil (c), pleurocystidia (d), cheilocystidia (e). Scale bars: $10 \mu \mathrm{m}$. 


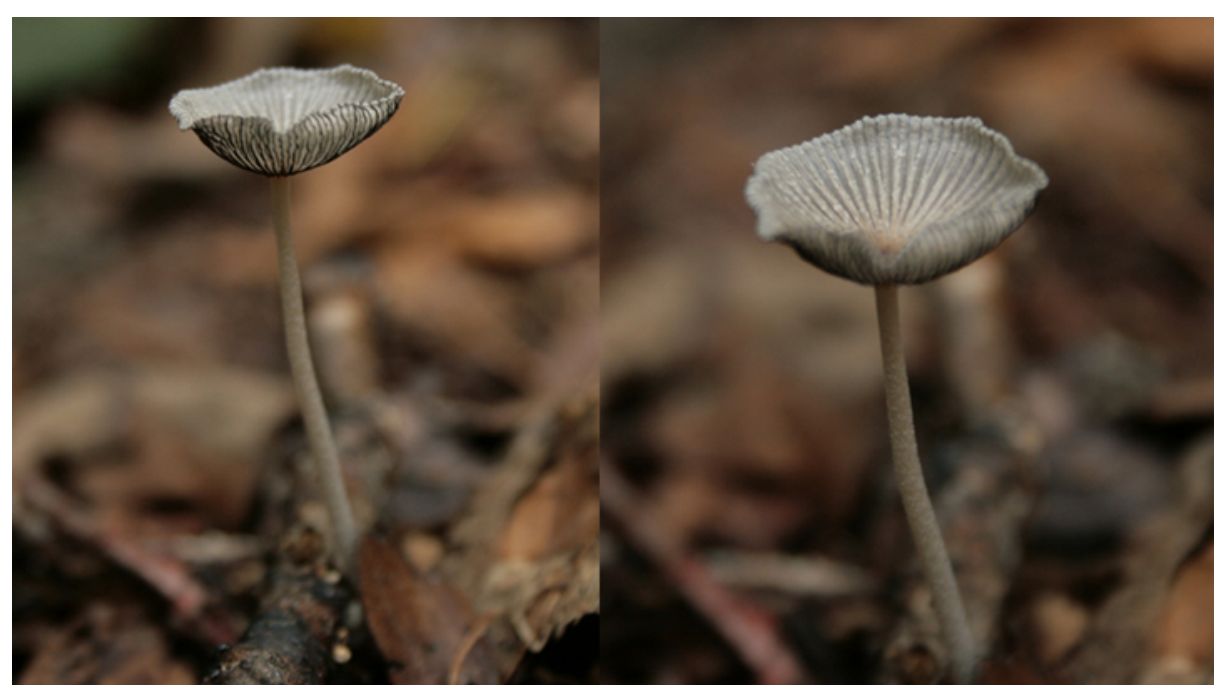

Fig. 27 Coprinopsis rugosobispora basidiocarps from Jankowo Gdańskie village (22.09.2012; photo by G. Neubauer).

SPECIMENS EXAMINED: (i) Poznań city, Budziszyńska street, ATPOL: BD-08, few basidiocarps on soil in garden, in grassy place, 24.07.2011, leg. \& det. B. Gierczyk (specimen: BGF/BG/110724/0011). (ii) 0.7 km NW from Jankowo Gdańskie village, ATPOL: DA-90, few basidiocarps on sticks, litter and rotten plants in mixed forest (Pinus sylvestris, Fagus sylvatica), 22.09.2012, leg. G. Neubauer, det. B. Gierczyk (specimen: BGF/BF/ GN/120922/0004).

DISTRIBUTION, HABITAT AND REMARKS. This is very rare species, previously known only from Belgium, Canada and the Netherlands. Until now it was found only on three localities, twice on woody debris and once on charcoal. Diverticulate veil, two-spored basidia and warty spores make this species easy to recognize. According to some authors (e.g. Ludwig [31]) it is only 2-spored variant of Coprinopsis phlyctidospora. Here we follow the concept of Uljé [20] and consider it as a separate taxon. The spores dimensions of these two species are practically the same. If Coprinopsis rugosobispora will be the form of the C. phlyctidospora with 2-spored basidia, one could expect the spores produced by this species will be distinctly larger. There was also molecular data, confirming that they are separate species [43].

Coprinopsis scobicola (P.D. Orton) Redhead, Vilgalys \& Moncalvo; Fig. 28 DESCRIPTION AND ICONOGRAPHY. [20]: 60-61; [22]: 38, 124-125, Fig. 49 \& 54; [40]: 195-196, Fig. 13.

MACROSCOPIC AND MICROSCOPIC FEATURES. Medium-sided species, pileus up to $40 \mathrm{~mm}$ when expanded, first campanulate to ellipsoid, then applanate, greyish, covered with white, fibrillose veil. Stipe white, up to $70 \times 3 \mathrm{~mm}$, somewhat flocculose. Spores broadly ellipsoid to ovoid, with central germ pore, 9.5-13.5 × 7.0-9.5 $\mu \mathrm{m}$ (lit. 9.5-16.5 × 7.0$10.5 \mu \mathrm{m}$ ). Basidia 2-spored, 18-30 × 8-11 $\mu \mathrm{m}$ (lit. 14-38 $\times 7-10 \mu \mathrm{m}$ ). Cheilocystidia 
a
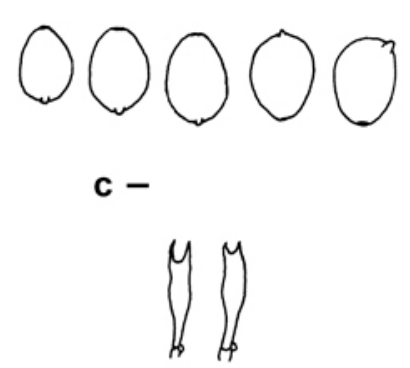

d -
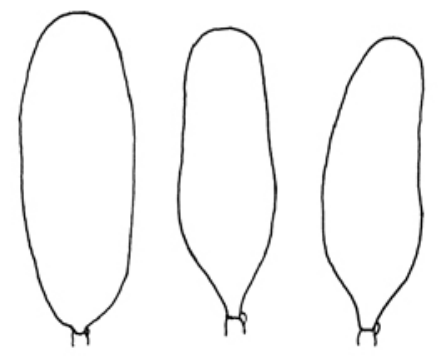
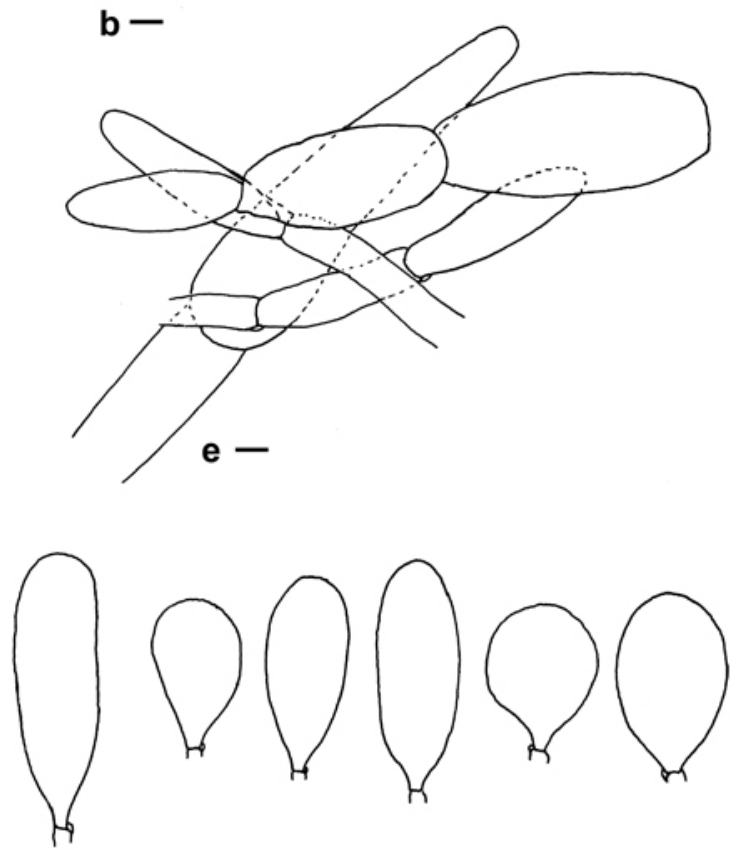

Fig. 28 Coprinopsis scobicola microcharacters: spores (a), veil (b), basidia (c), pleurocystidia (d), cheilocystidia (e). Scale bars: $10 \mu \mathrm{m}$.

variable, subglobose, utriform, subcylindrical, ellipsoid or ovoid 30-70 $\times 20-40 \mu \mathrm{m}$ (lit. 35-75 $\times 17-38 \mu \mathrm{m}$ ). Pleurocystidia ellipsoid to cylindrical, 75-120 $\times 30-35 \mu \mathrm{m}$ (lit. $70-110 \times 26-37 \mu \mathrm{m})$. Veil composed of cylindrical to fusiform elements, up to $40 \mu \mathrm{m}$ wide. Clamps present.

SPECIMEN EXAMINED. Poznań city, Bułgarska street near the crossroads with Marcelińska street, ATPOL: BD-08, a dozen of basidiocarps on woodchips and sawdust used as litter on flowerbeds, 21.07.2012, leg. \& det. B. Gierczyk (specimen: BGF/ BG/120721/0001, basidiocarps have been observed since May to September).

DISTRIBUTION, HABITAT AND REMARKS. This is very rare species, previously known only from Great Britain and the Netherlands. It has been found on sawdust, woodchips and compost in unheated greenhouses. The finding in Poland is the first outside the buildings. The second species with cylindrical veil elements and 2-spored basidia, Coprinopsis bicornis, grows on dung and forms the smaller basidiocarps covered with the veil composed of cylindrical and subglobose elements.

Coprinopsis spilospora (Romagn.) Redhead, Vilgalys \& Moncalvo; Fig. 29, Fig. 30 DESCRIPTION AND ICONOGRAPHY. [20]: 83; [30]: 89, Tab. 275, Fig. 93.89; [31]: 249-250.

MACROSCOPIC AND MICROSCOPIC FEATURES (COLL. 2): Basidiomata mediumsized, up to $45 \mathrm{~mm}$ when expanded, first subglobose or broadly campanulate, then convex, 


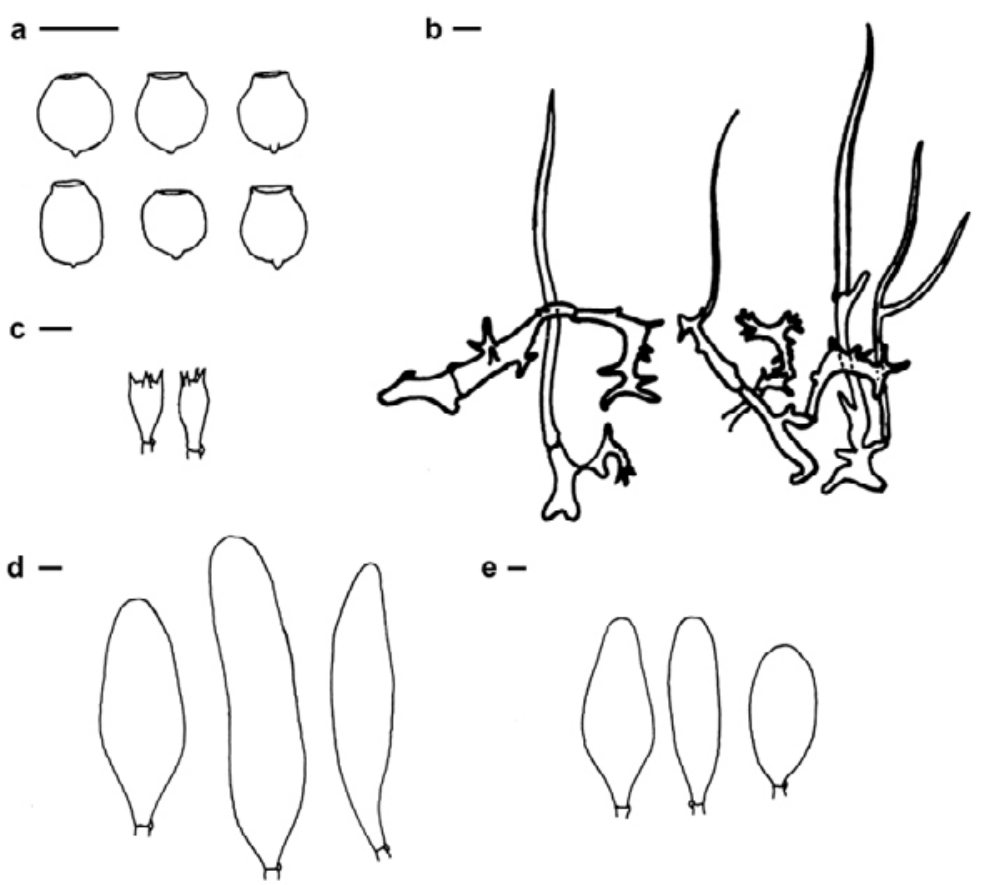

Fig. 29 Coprinopsis spilospora microcharacters: spores (a), veil (b), basidia (c), pleurocystidia (d), cheilocystidia (e). Scale bars: $10 \mu \mathrm{m}$.

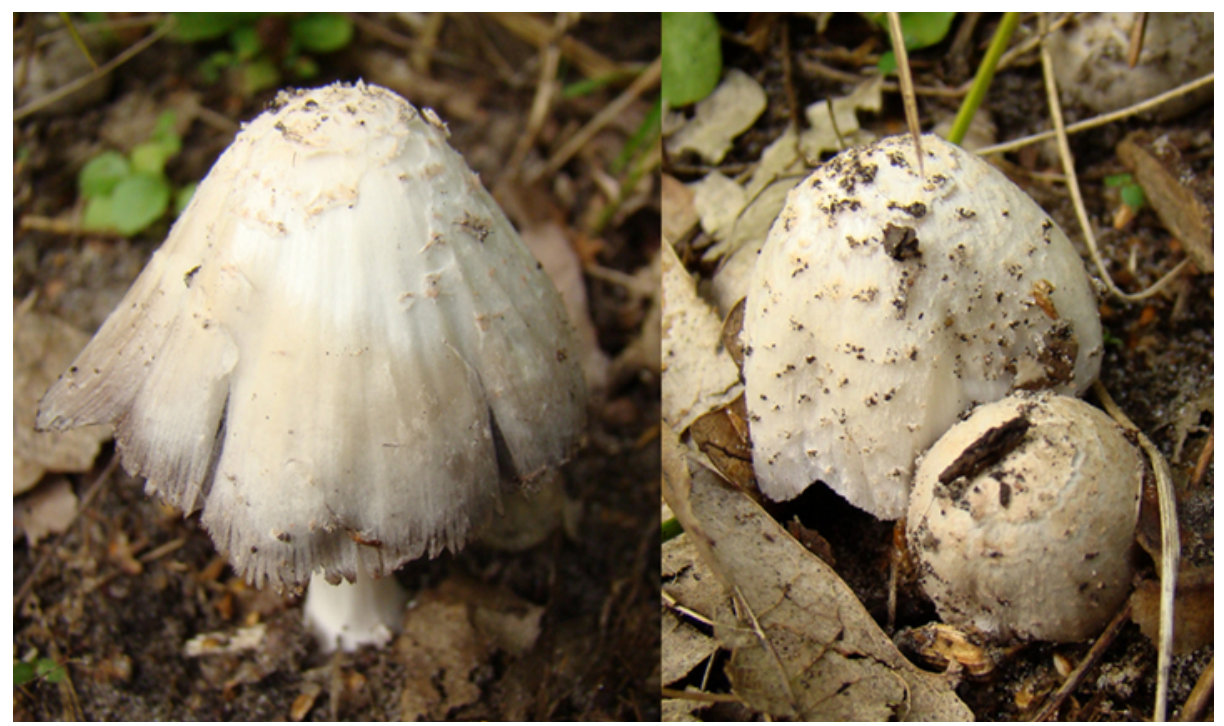

Fig. 30 Coprinopsis spilospora basidiocarps from Puszcza Knyszyńska forest (29.09.2012; photo by M. Gryc). 
whitish, grey to ocher, covered with flocks of veil. Veil white with brown or rusty tips. Stipe up to $70 \times 4 \mathrm{~mm}$, white. Spores subglobose to rounded quadrangular, somewhat trapezoid, 7.5-9.0 × 6.0-9.0 $\mu \mathrm{m}$ (lit. 7.3-9.7 × 5.6-9.3 $\mu \mathrm{m}$ ), flattened and truncate, with very broad, central germ pore and distinct plague. Germinating spore walls opening with jagged edges. Basidia 4-spored, 20-35 ×9-10 $\mu \mathrm{m}$ (lit. 22-36 ×8.5-10 $\mu \mathrm{m})$. Cheilocystidia utriform to fusiform, $60-120 \times 30-50 \mu \mathrm{m}$. Pleurocystidia utriform, conical narrowly ellipsoid or fusiform, 70-180 × 30-65 $\mu \mathrm{m}$ (lit. 80-200 × 25-60 $\mu \mathrm{m}$ ). Veil composed of thick-walled hyphae (walls up to $3 \mu \mathrm{m}$ ), strongly diverticulate, with long hair-form ends up to $200 \mu \mathrm{m}$. Clamps present.

SPECIMENS EXAMINED. (i) Gdańsk City, Oliwa district, near children Hospital "Polanki”, ATPOL: DA-80, few basidiocarps on soil in park, on clearing under Carpinus betulus, 11.05.2012, leg. G. Neubauer, det. B. Gierczyk (specimen: BGF/BF/GN/120511/0001). (ii) Puszcza Knyszńska Forest, $0.5 \mathrm{~km}$ S from Krasny Las forest ranger's lodge, ATPOL: GC-11, one basidiocarp on the roadside in the mixed forest, 13.06.2010, leg. M. Gryc, det. B. Gierczyk (specimen: BGF/BF/MG/100613/0001). (iii) Puszcza Knyszńska Forest, $1.5 \mathrm{~km}$ S from Krasny Las forest ranger's lodge, ATPOL: GC-12, few basidiocarps on the side of forest road near deciduous trees, 12.05.2012 \& 29.09.2012, leg. M. Gryc, det. B. Gierczyk (specimens: BGF/BF/MG/120512/0001 \& BGF/BF/MG/120929/0005).

DISTRIBUTION, HABITAT AND REMARKS. This is very rare species, previously known only from scattered localities in Europe (Italy, Germany, Hungary, France, Finland, Norway and Sweden), where it was found on soil, saw-dust and burnt places in deciduous forests and lawns. From somewhat similar species, Coprinopsis gonophylla, it differs mainly in spores shape (C. gonophylla produces subglobose spores without the plague) and presence of setae-like terminal elements in veil.

Coprinus palmeranus Bogart; Fig. 31, Fig. 32

DESCRIPTION AND ICONOGRAPHY. [44]: 248-252, Fig. 4; [45]: 105-107, Fig. 4 (as Coprinus sp.); [46]: 95-97, Fig. 1.

MACROSCOPIC AND MICROSCOPIC FEATURES [COLL. (ii)]. Basidiomata rather large, expanded pileus up to $30-40 \mathrm{~mm}$, first ovoid to ellipsoid, then conic, campanulate to flat or revolute, stipe $40-70 \times 3-5 \mathrm{~mm}$, hollow, with bulbous base and distinct rhizomorphs. Young cap white with pale yellow-brown center, with age becoming greyish with brown center, covered with numerous yellowish-brown veil scales. Stipe white, with thin white, membranous annulus. Spores 6.5-9.5 × 4.5-6.5 $\mu \mathrm{m}$ (lit. 6.5-12.0 × 5.0-7.0 $\mu \mathrm{m})$, broadly ellipsoid, dark grey, with distinct, eccentric germ pore. Basidia 4-spored,

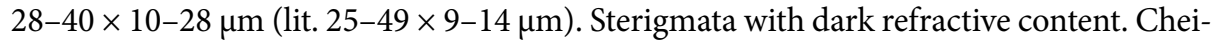
locystidia globose, obovate, ellipsoid or lageniform, 15-70 × 10-30 $\mu \mathrm{m}$ (lit. 10-55 × 10-25 $\mu \mathrm{m})$, often catenate. Pleurocystidia and other cystidia absent. Veil composed of chains of cylindrical, constricted at septa, hyaline, thin-walled elements, up to 50-20 $\mu \mathrm{m}$. Clamps scarce in flesh context, but absent at the base of basidia.

SPECIMENS EXAMINED. (i) Izerskie foothils, Łupki village, near hostel, ATPOL: AE-59, one basidiocarp on lawn, on calcareous soil, 06.10.2011, leg. J. Soboń, det. B. Gierczyk (specimen: BGF/BF/JS/111006/0001). (ii) Kaczawskie Mts., Sobocin limestone quarry near Mysłów village, ATPOL: BE-61, a dozen of basidiocarps on xerothermic grassland belonging to Brometalia erecti, on $\mathrm{CaCO}_{3}$-rich soil mixed with pieces of limestone, 04.10.2008, leg. \& det. B. Gierczyk (specimen: BGF/081004/0006). 


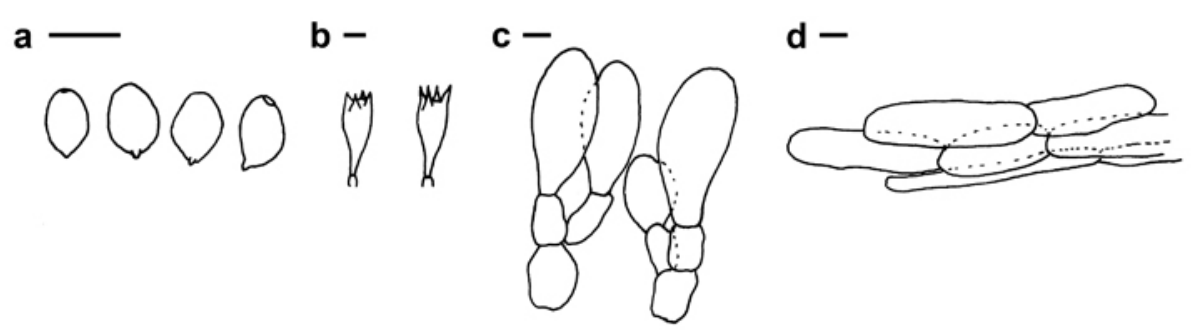

Fig. 31 Coprinus palmeranus microcharacters: spores (a), basidia (b), cheilocystidia (c), veil (d). Scale bars: $10 \mu \mathrm{m}$.

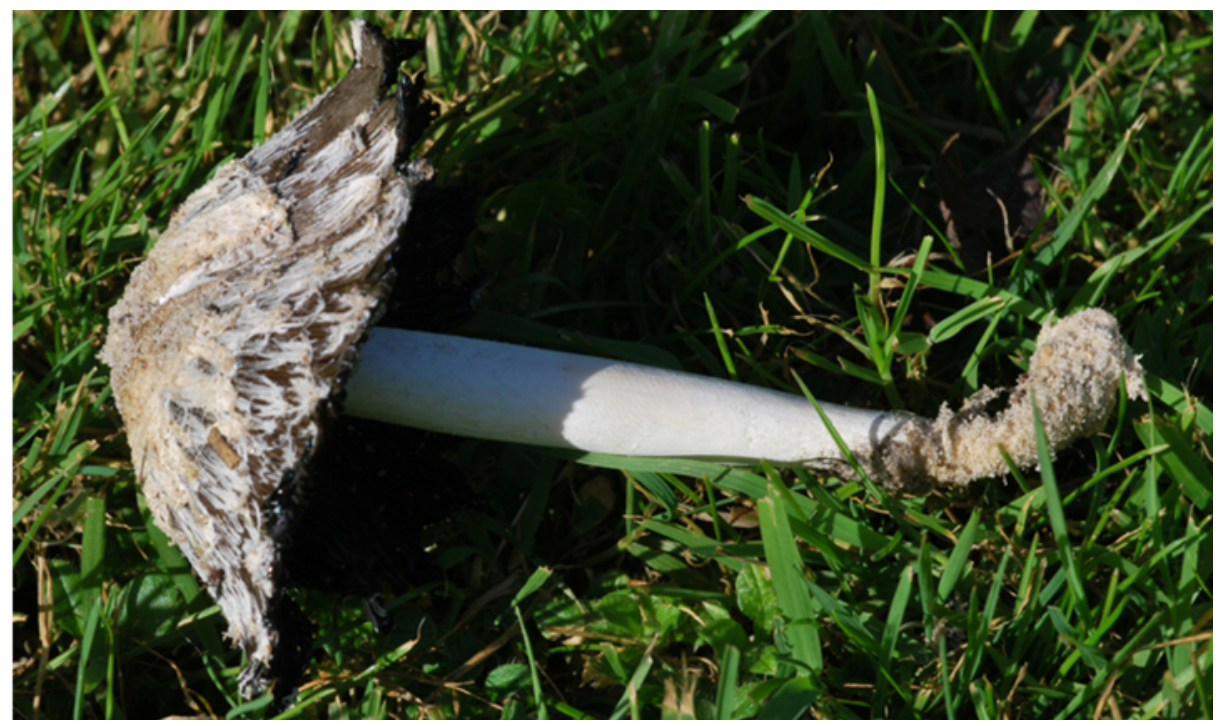

Fig. 32 Coprinus palmeranus basidiocarps from Łupki village (06.10.2011; photo by J. Soboń).

DISTRIBUTION, HABITAT AND REMARKS. This species has been described from USA (Washington), in open grassy maple wood, on clay soil by Bogart [33] as the fungus of "bears and striking resemblance to C. comatus in its overall appearance. It differs mainly in its much smaller stature and the much smaller size of the spores and basidia”. Until now in Europe it was found only in Italy, on sands, in grasslands $[45,46]$.

\section{Conclusions}

Over the last decade the number of Coprinus species known from Poland has doubled. Till 2003 only 50 species were mentioned from this territory [12], comparing to over 150 
species known from Europe. In 2011, after publication of the first papers of Gierczyk et al. $[13,14]$, the number of Coprinus species in Polish biota has risen to 83 . In the current paper we present descriptions, ecological notes and localities of further 19 species of coprinoid fungi, hitherto not mentioned from Poland. In the consequence, the number of Coprinus species representatives in Polish biota has now reached 102. Among the species, found in years 2010-2013, 9 have been found at one locality while only 4 at least three localities. This indicates the rarity of all of the species described. The fungi mentioned in this paper inhabit various substrates. Eight of them (Coprinellus bisporiger, C. dilectus, Coprinopsis coniophora, C. goudensis, C. krieglsteineri, C. phlyctidospora, C. rugosobispora, C. scobicola) grow on woody material: tree logs, sticks, shavings and sawdust. The other nine species grow on soil and among litter (Coprinellus heterothrix, Coprinopsis bellulus, C. cinereofloccosa, C. idae, C. pachyderma, C. rugosobispora, C. spilospora, C. iocularis, Coprinus palmeranus) while three species are coprophilous (Coprinellus radicellus, Coprinopsis annulopora, C. candidolanata). Although the knowledge about the biota of the coprinoid fungi of Poland has significantly increased in recent years, further studies are required as the occurrence of other several dozen of species is expected within this area.

\section{Acknowledgments}

Authors wish to thank Waldemar Czerniawski, Grażyna Domian, Mirosław Gryc, Anna Hreczka, Barbara Kudławiec, Bogusław Mazurek, Grzegorz Neubauer, Jacek Nowicki, Jacek Soboń and Mirosław WantochRekowski, the participants of the mycological discussion-board (http://www.bio-forum.pl) as well as Bogdan Jaroszewicz and Alicja Wiktoruk from Białowieża Geobotanical Station of Warsaw University, for collecting and sending ink-cap specimens. Our gratitude goes also to the authorities of Bieszczadzki National Park and Biebrzański National Park for permissions to collect materials used in this study. We wish also to thank Waldemar Czerniawski, Grażyna Domian, Mirosław Gryc, Anna Hreczka, Barbara Kudławiec, Krzysztof Kujawa, Grzegorz Neubauer, Jacek Nowicki, Jacek Soboń and Mirosław Wantoch-Rekowski for ink-cap photographs. This project was supported by the following sources: private funds (BG, AK, AS), statutory funds of Warsaw University of Life Sciences - SGGW (AS) and statutory funds of Institute for Agricultural and Forest Environment, Polish Academy of Sciences, research topic: "Evaluation of distribution and threats of macromycetes in Poland" (AK).

\section{Authors' contribution}

The following declarations about authors' contributions to the research have been made: developing the conception of work: BG; field research: BG, AK, AS; species identification: BG, AK; manuscript preparation: BG, AK, AS.

\section{References}

1. Hopple JS, Vilgalys R. Phylogenetic relationships in the mushroom genus Coprinus and dark-spored allies based on sequence data from the nuclear gene coding for the large ribosomal subunit RNA: divergent domains, outgroups, and monophyly. Mol Phylogenet Evol. 1999;13(1):1-19. http://dx.doi.org/10.1006/ mpev.1999.0634

2. Moncalvo JM, Vilgalys R, Redhead SA, Johnson JE, James TY, Aime MC, et al. One hundred and seventeen clades of euagarics. Mol Phylogenet Evol. 2002;23(3):357-400. http://dx.doi.org/10.1016/ s1055-7903(02)00027-1

3. Padamsee M, Matheny PB, Dentinger BTM, McLaughlin DJ. The mushroom family Psathyrellaceae: evidence for large-scale polyphyly of the genus Psathyrella. Mol Phylogenet Evol. 2008;46(2):415-429. http://dx.doi.org/10.1016/j.ympev.2007.11.004

4. Larsson E., Örstadius L. Fourteen coprophilous species of Psathyrella identified in the Nordic countries using morphology and nuclear rDNA sequence data. Mycol Res. 2008;112(10):1165-1185. http://dx.doi. org/10.1016/j.mycres.2008.04.003

5. Nagy GL, Kocsubé S, Papp T, Vágvölgyi C. Phylogeny and character evolution of the coprinoid mushroom 
genus Parasola as inferred from LSU and ITS nrDNA sequence data. Persoonia. 2009;22:28-37. http:// dx.doi.org/10.3767/003158509X422434

6. Nagy LG, Vágvölgyi C, Papp T. Type studies and nomenclatural revisions in Parasola (Psathyrellaceae) and related taxa. Mycotaxon. 2010;112:103-141. http://dx.doi.org/10.5248/112.103

7. Nagy LG, Urban A, Örstadius L, Papp T, Larsson E, Vágvölgyi C. The evolution of autodigestion in the mushroom family Psathyrellaceae (Agaricales) inferred from maximum likelihood and Bayesian methods. Mol Phylogenet Evol. 2010;57(3):1037-1048. http://dx.doi.org/10.1016/j.ympev.2010.08.022

8. Nagy LG, Walther G, Házi J, Vágvölgyi C, Papp T. Understanding the evolutionary processes of fungal fruiting bodies: correlated evolution and divergence times in the Psathyrellaceae. Syst Biol. 2011;60(3):303-317. http://dx.doi.org/10.1093/sysbio/syr005

9. Nagy LG, Házi J, Szappanos B, Kocsubé S, Bálint B, Rákhely G, Vágvölgyi C, Papp T. The evolution of defense mechanisms correlate with the explosive diversification of autodigesting Coprinellus mushrooms (Agaricales, Fungi). Sys Biol. 2012;61(4):595-607. http://dx.doi.org/10.1093/sysbio/sys002

10. Nagy LG, Házi J, Vágvölgyi C, Papp T. Phylogeny and species delimitation in the genus Coprinellus with special emphasis on the haired species. Mycologia. 2012,104(1):254-275. http://dx.doi.org/10.3852/11-149

11. Nagy LG, Desjardin DE, Vágvölgyi C, Kemp R, Papp T. Phylogenetic analyses of Coprinopsis sections Lanatuli and Atramentarii identify multiple species within morphologically defined taxa. Mycologia. 2013;105(1):112-124. http://dx.doi.org/10.3852/12-136

12. Wojewoda W. Checklist of Polish larger Basidiomycetes. Kraków: W. Szafer Institute of Botany, Polish Academy of Sciences; 2002. (Biodiversity of Poland; vol. 7).

13. Gierczyk B, Chachuła P, Karasiński D, Kujawa A, Kujawa K, Pachlewski T, et al. Grzyby wielkoowocnikowe polskich Bieszczadów. Część I. Parki Nar Rez Przyr. 2009;28(3):3-100.

14. Gierczyk B, Kujawa A, Pachlewski T, Szczepkowski A, Wójtowski M. Rare species of the genus Coprinus Pers. s. lato. Acta Mycol. 2011;46(1):27-73. http://dx.doi.org/10.5586/am.2011.003

15. Kujawa A. Grzyby makroskopijne Polski w literaturze mikologicznej [Internet]. Atlas grzybów Polski. 2013 [cited 2014 Feb 20]; Available from: http://www.grzyby.pl/grzyby-makroskopijne-Polski-w-literaturzemikologicznej.htm

16. Clémençon H. Methods for working with macrofungi: laboratory cultivation and preparation of larger fungi for light microscopy. Eching: IHW-Verlag; 2009.

17. Vesterholt J. Coprinellus P. Karst. In: Knudsen H, Vesterholt J, editors. Funga Nordica. Agaricoid, boletoid and cyphelloid genera. Copenhagen: Nordsvamp; 2008. p. 558-568.

18. Vesterholt J. Coprinopsis P. Karst. In: Knudsen H, Vesterholt J, editors. Funga Nordica. Agaricoid, boletoid and cyphelloid genera. Copenhagen: Nordsvamp; 2008. p. 568-583.

19. Vesterholt J. Coprinus Pers. In: Knudsen H, Vesterholt J, editors. Funga Nordica. Agaricoid, boletoid and cyphelloid genera. Copenhagen: Nordsvamp; 2008. p. 532-533.

20. Uljé CB. Coprinus. In: Noordeloos ME, Kuyper TW, Vellinga EC, editors. Flora Agaricina Neerlandica. Critical monograps on families of agarics and boleti occurring in the Netherlands. Boca Raton, FL: Taylor \& Francis; 2005. p. 22-109. (vol 1).

21. Robert V, Stegehuis G, Stalpers J. The MycoBank engine and related databases [Internet]. 2014 [cited 2014 Feb 20]; Available from: http://www.mycobank.org

22. Orton PD, Watling R. Coprinaceae. Part 1: Coprinus. Edinburgh: Her Majesty’s Stationery Office; 1979. (British Fungus Flora. Agarics and Boleti; vol 2).

23. Doveri F. Fungi fimicoli italici. A guide to the recognition of basidiomycetes and ascomycetes living on faecal material. Vicenza: A.M.B. Fondazione Centro Studi Mycologici; 2004.

24. Enderle M. Die Pilzflora des Ulmer Raumes. Ulm: Verein für Naturwiss. und Mathematik; 2004.

25. Legon NW, Henrici A, Roberts PJ, Spooner BM, Watling R. Checklist of the British \& Irish Basidiomycota. Kew: Royal Botanic Gardens; 2005.

26. Červenka J. Coprinus annuloporus Enderle. Atlas húb [Internet]. 2007 [cited 2014 Feb 20]; Available from: http://www.nahuby.sk/atlas-hub/Coprinus-annuloporus/hnojnik/hnojnik/ID2789 
27. Nagy GL, Gorliczai ZS. Novel data to the knowledge of the fungi of the Great Hungarian Plain. Clusiana 2007;46:67-113.

28. Keirle MR, Hemmes DE, Desjardin DE. Agaricales of the Hawaiian Islands. 8. Agaricaceae: Coprinus and Podaxis; Psathyrellaceae: Coprinopsis, Coprinellus and Parasola. Fung Div. 2004;15:33-124.

29. Házi J, Nagy LG, Vágvölgyi C, Papp T. Coprinellus radicellus, a new species with northern distribution. Mycol Prog. 2010;10(3):363-371. http://dx.doi.org/10.1007/s11557-010-0709-y

30. Ludwig E. Pilzkompendium. Band 2. Abbildungen. Die größeren Gattungen der Agaricales mit farbigem Sporenpulver (ausgenommen Cortinariaceae). Berlin: Fungicon-Verlag; 2007.

31. Ludwig E. Pilzkompendium. Band 2. Beschreibungen. Die größeren Gattungen der Agaricales mit farbigem Sporenpulver (ausgenommen Cortinariaceae). Berlin: Fungicon-Verlag; 2007.

32. Uljé CB. Atlas grzybów Polski [Internet]. C.B. Uljé website on coprinoid fungi. 2001 [cited 2014 Feb 20]; Available from: http://www.grzyby.pl/coprinus-site-Kees-Uljee/cindex.htm

33. Moser M, Bellú F, Hausknecht A, Pelntner U. Farbatlas der Basidiomyceten. Berlin: Spektrum Akademischer Verlag Heidelberg; 2002.

34. Schafer D. Coprinus dilectus Fr. sensu Josserand. Field Mycol. 2009;10(1):15-18. http://dx.doi.org/10.1016/ s1468-1641(10)60491-4

35. Heinemann P, Josserand M. Copinus erythrocephalus and Coprinus dilectus. Bull Soc Mycol Fr. 1941;57:36-49.

36. Breitenbach J, Kränzlin F. Fungi of Switzerland. Vol. 4. Agarics. Lucern: Richmond Publishing Company; 1995.

37. Schafer D. Coprinus heterothrix and C. cinnamomeotinctus. Field Mycol. 2012;13(3):99-104. http://dx.doi. org/10.1016/j.fldmyc.2012.06.012

38. Uljé CB. Four new species of Coprinus from the Netherlands. Persoonia. 1988;13(4):479-488.

39. Kits van Waveren E. The "stercorarius group" of the genus Coprinus. Persoonia. 1968;5(2):131-176.

40. Uljé CB, Noordeloos ME. Studies in Coprinus. V - Coprinus section Coprinus. Revision of subsection Lanatuli Sing. Persoonia. 1999;17(2):165-199.

41. van de Bogart F. The genus Coprinus in western North America. Part II: section Lanatuli. Mycotaxon. 1979;8(1):243-291.

42. Schafer D. Coprinus species at the Grantley Hall foray. Field Mycol. 2001;2(1):25-28. http://dx.doi. org/10.1016/s1468-1641(10)60088-6

43. Raut JK, Suzuki A, Fukiharu T, Shimizu K, Tanaka C, Takeshige S. A new record of an ammonia fungus, Coprinopsis rugosobispora collected from urea-treated boreal forest in Canada. Proceeding of the 6th meeting of East Asia for collaboration on edible fungi; 2010.

44. van de Bogart F. The genus Coprinus in western North America. Part I: section Coprinus. Mycotaxon. 1976;4(1):233-275.

45. Hausknecht A, Zuccherelli A. Ritrovamenti interessanti dal Ravannate. 5a parte: diverse Agaricales, nuovi reperti e aggiunte a gruppi già trattati e altri. Boll Gruppo Micol G Bres. 1998;41(2):91-134.

46. Hausknecht A. Coprinus palmeranus - neu für Europa. Österr Z Pilzk. 2004;13:95-99. 